\title{
Article \\ Correlation between Fractal Dimension and Areal Surface Parameters for Fracture Analysis after Bending-Torsion Fatigue
}

\author{
Wojciech Macek (iD \\ Faculty of Mechanical Engineering and Ship Technology, Gdańsk University of Technology, \\ 80-233 Gdańsk, Poland; wojciech.macek@pg.edu.pl
}

Citation: Macek, W. Correlation between Fractal Dimension and Areal Surface Parameters for Fracture Analysis after Bending-Torsion Fatigue. Metals 2021, 11, 1790. https://doi.org/10.3390/ met11111790

Academic Editor:

Alberto Campagnolo

Received: 15 October 2021

Accepted: 4 November 2021

Published: 7 November 2021

Publisher's Note: MDPI stays neutral with regard to jurisdictional claims in published maps and institutional affiliations.

\begin{abstract}
This paper investigates the fracture surface topography of two steel and aluminum alloys subject to bending-torsion fatigue loadings, as well as their susceptibility to fatigue performance and failure mechanisms. Using fracture surface topography data analysis, elements with different geometries were elaborated. A correlation between the fractal dimension, other selected parameters of surface topography such as areal $S x$, and fatigue loading conditions was found. Distinctions in particular regions of cracks were also recognized through proving the correctness and universality of the total fracture surface method. The influence of fatigue loading parameters on the surface topography of fatigue fractures was demonstrated. For the analyzed cases, results show that the fractal dimension and standard surface topography parameters represent a correlation between them and loading conditions. As a single parameter, the appropriate loading ratio cannot be outright calculated with fractal dimension, but can be estimated with some approximation, taking into account additional assumptions.
\end{abstract}

Keywords: fracture; surface topography; fractal dimension; bending-torsion fatigue; steel; aluminium alloy

\section{Introduction}

Many service failures occur from components being subjected to mixed-mode multiaxial fatigue loadings. A representative illustration of external loading in engineering application is a transverse plane from a tubing shaft surface under bending-torsion loading [1]. In the appearance of such complex loading as bending with torsion, these fields are liable to fatigue failure and, therefore, the analysis of fracture surfaces based on fractographic measurements may be a significant engineering tool to improve design, preventing future failures.

The fractographic study is the primary post-failure step in the fatigue failure analysis of metallic components [2-5]. The relationship between the materials microstructure and service loadings in material cracking processes has been analyzed in the literature [6-8]. In particular, fractographic techniques of total fracture areas for quantitative failure analyses have been used relatively rarely in various scientific fields [9,10], such as for dental implant materials [11,12]. Also, a small number of references can be found on the subject of the fractography of elements subjected to bending-torsion fatigue [13-16].

At the end of the 20th century, the scientific and engineering world came to the conclusion that presenting surface irregularities in only two dimensions was insufficient $[17,18]$. All interactions of surfaces are spatial, which also applies to the fractal dimension $[19,20]$, and so research into the analysis of inequalities in three dimensions was initiated. We can find many papers reporting ways of presenting surfaces in a 3D system to describe the surfaces of additive manufactured metals [21], machining results [22] and fretting wear [23]. In all of these studies, digital filtering is very important and has a great influence on the calculation of results for the surface parameters [24-26]. The most common filtration technique to neutralize waviness and form involves Gaussian filters, characterised in the ISO standard [27]. 
In addition to the typical areal surface topography parameters, the fractal dimension [28-30] for surface description is also used in many scientific fields, including fractography and crack propagation [31-35]. The box-counting procedure in particular is one of the frequently operated methods to calculate fractal dimensions. Therefore, taking into account the tendency of the quantitative investigation, the accessibility of the optical method, and the diversity of materials, forms and loadings, this paper tries to indicate a common and straightforward method for identifying the causes of failure. In the context of filters, for the fractal dimension, and especially the enclosing boxes method, filters should be applied on the primary surface. This means that the surface should be prepared for analysis, so the microroughness $\lambda s$ must be removed along with the form or slope $\lambda c$, using levelling operations. After levelling, the angle no longer has any impact on the fractal dimension parameter.

This paper is based on the promising results based on fractal dimension analysis, partially presented previously by the author [36,37]. The study compares fractal dimension with the surface areal parameters, despite different recommendations, and without the use of surface primary filters. The analysed surfaces are fatigue fractures after bending, torsion and a combination of these loadings. This analysis would help to interpret the connections between fracture surface topography and trying to determine the models between fractal dimension and fatigue loading conditions.

\section{Materials and Methods}

\subsection{Fatigue Test Materials and Campaign}

10HNAP and S355J2 steels and 2017-T4 aluminium alloy were investigated, and also described earlier in this set by Macek et al. [37,38]. A nominal composition and mechanical features, such as Young modulus $E-215,210,72 \mathrm{GPa}$ and Yield stress $\sigma_{y}-418$, $358,382 \mathrm{MPa}$, for 10HNAP and S355J2 steels and 2017-T4 aluminium alloy, respectively, are shown in these works. Fatigue experiments were conducted on the specimens shown in Figure 1. Two V-notched configurations and one (S355J2) smooth profile were used. The tests were run for three categories of loading: (1) pure bending, (2) combined torsion with bending, and (3) pure torsion.

Proportional and non-proportional, but also constant-amplitude and random loading programs, were used. The 10HNAP steel specimens were tested with stationary and ergodic random loadings and had a normal probability distribution and wide-band frequency spectra from 0 to $60 \mathrm{~Hz}$. Fatigue tests of S355J2 steel specimens included non-proportional bending-torsion histories. In the case of the 2017A-T4 aluminium alloy specimens, tests were conducted under different stress ratios $R$. To compare the various instances, the loading stress ratio, $r$, was determined by Equation (1).

$$
r=\frac{\tau_{\max }}{\sigma_{\max }+\tau_{\max }},
$$

where $r=1$ is related to pure torsion, $r=0$ to pure bending and $0<r<1$ to bending and torsion combination. The values of the loading stress ratio $r$ and stress ratios $R$ studied in the fatigue tests are shown in Table 1 [37].

Table 1. Fatigue tests parameters.

\begin{tabular}{cccc}
\hline Material & $r=\frac{\tau_{\max }}{\sigma_{\max }+\tau_{\max }}$ & $R=\frac{\sigma_{\min }}{\sigma_{\max }}$ & Reference \\
\hline 10HNAP & $0 ; 0.5 ; 1$ & -1 & {$[14]$} \\
S355J2 & $0 ; 0.16-0.6 ; 1$ & -1 & {$[39]$} \\
$2017-\mathrm{T} 4$ & $0 ; 0.18-0.44 ; 1$ & $-1 ;-0.5 ; 0$ & {$[40]$} \\
\hline
\end{tabular}



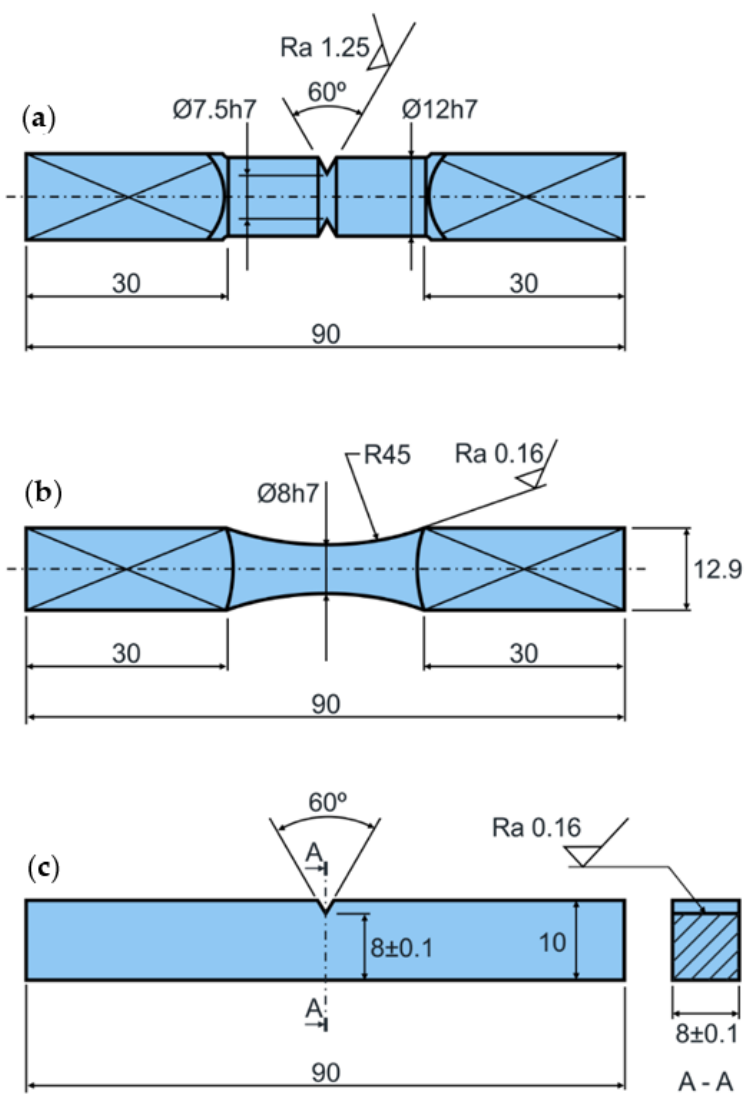

Figure 1. Specimen geometries utilised in fatigue campaign: (a) 10HNAP steel, (b) S355J2 steel, and (c) 2017-T4 aluminium alloy (dimensions in millimetres). Adapted from [37].

\subsection{Fracture Surface Topography Measurement}

Surface topographies were investigated via the Infinite Focus G4 optical measuring system (Alicona Imaging $\mathrm{GmbH}$, Graz, Austria), using focus variation technology [38,41]. The evaluation of 3D scans, for entire fracture areas, was carried out with magnification of $10 \times, 79.3 \mathrm{~nm}$ vertical resolution, and $3.91 \mu \mathrm{m}$ lateral resolution. Settings were applied to generate 3D surface image datasets of the investigated fractures. The measurement results were also analysed with MountaisMap Premium 7.4 software (Digital Surf, Besançon, France). Alicona ( ${ }^{*}$.al3d) files were converted into height maps without applying filters. The total area of the fracture was chosen for imaging according to the entire fracture method [37]. Additional measurements of the characteristic zones were made with $100 \times$ magnification.

The whole current surface of specimens made of 10HNAP steel was trimmed to a rounded region of interest (ROI) with a diameter of $7.2 \mathrm{~mm}$ (see Figure 2), to exclude the edges, distinct break in physical continuity and non-measured points. For aluminium alloy specimens, the surface was reduced to a rectangle with an area of dimensions $7.2 \mathrm{~mm} \times 7.5 \mathrm{~mm}$, and for analysed S355J2 cases, the area was cropped to a circle with a diameter of $7.8 \mathrm{~mm}$. 


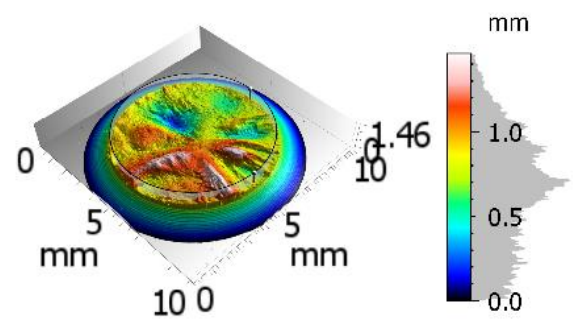

(a)

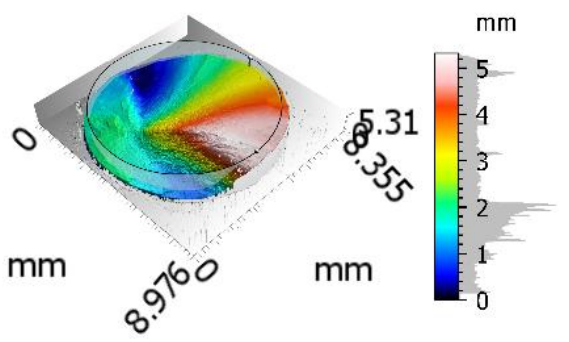

(b)

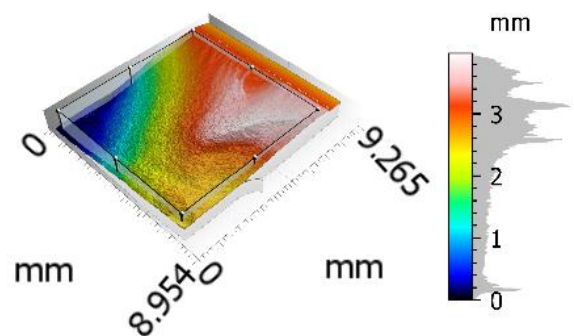

(c)

Figure 2. Methodology used to select the region of interest-ROI (all shown examples of fracture surfaces are for the bending-torsion case): (a) 10HNAP steel, (b) S355J2 steel, and (c) 2017-T4 aluminium alloy.

3D fractography investigation was performed on the fracture area implementing fractal dimension $D f$ with the enclosing boxes method (EBM), as well as height parameters according to ISO 25178. The fractal dimension $D f$ was calculated from the extracted ROI (Figure 2) with EBM, for resolutions of 59 points in the plot, as presented in Figure 3. EBM divides the sections into smaller subsections with width $\varepsilon$, and computes the field $A \varepsilon$ of all fields in an overlay the entire region [42,43]. This is a repeated action in which the width of the field is transitioned to the plot $\ln (A \varepsilon) / \ln (\varepsilon)$. EBM in real units uses real Z-spacing values to calculate the enclosed area. To estimate the fractal dimension $D f$ a line is fitted using the least-squares method. The absolute value of the slope of the (red) line is the estimation of fractal dimension $D f$. For the example shown in Figure 3, the slope value is -2.122 , and thus the fractal dimension $D f=2.122$. The coefficient of determination $R^{2}$ for the case analyzed in Figure 3 was 0.9998. In general, a surface with a smaller fractal dimension is less complex and closer to a plane than a surface with a higher value, which is closer to a volume. The fractal dimension $D f$ of the areal surface is higher than 2 and smaller than 3. For comparative analysis in the context of the fractal dimension, $D f$ and loading stress ratio $r$, the parameters $S a, S q, S z$ were also taken into account. Additionally, for cases with extreme $D f$ values, the volume $V x$ and $S k$ parameters were analysed. The $S q$ parameter (see Equation (2)) is a root mean square (RMS) height value of surface, and $\mathrm{Sa}$ (see Equation (3)) is the arithmetical mean of the absolute surface heights, according to ISO 25178. Maximum height of surface $S z$ is the sum of the maximum peak height $S p$ and maximum pit height $S v$, presented in Figure 4a [14].

$$
\begin{gathered}
S q=\sqrt{\frac{1}{A} \iint_{A} z^{2}(x, y) d x d y,} \\
S a=\frac{1}{A} \iint_{A}|z(x, y)| d x d y,
\end{gathered}
$$

where: $A$ 一the definition area; $z$-surface height in position $x, y ; x, y$-lengths in perpendicular directions.

Figure 4 visualizes how ISO 25178 functional volume parameters are calculated from the Abbott-Firestone curve. Figure 4a, with 10HNAP $(r=0)$ specimen shows how to convert extracted surface (ROI) into a series of profiles. Figure $4 \mathrm{~b}$ presents volume parameters in relation to profiles and the Abbott-Firestone curve (see red line). The $V x$ family constitute the valley void volume $V v v$, the core void volume $V v c$, the peak material volume $V m p$, and the core material volume $V m c$. The default material ratios used to calculate these parameters are 10 and $80 \%$ [44]. 


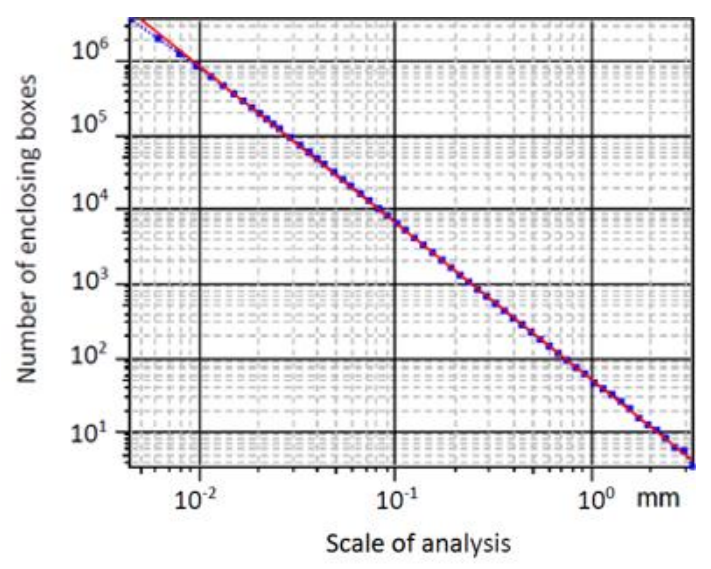

Figure 3. Fractal analysis plot for exemplary fracture surface.

(a)

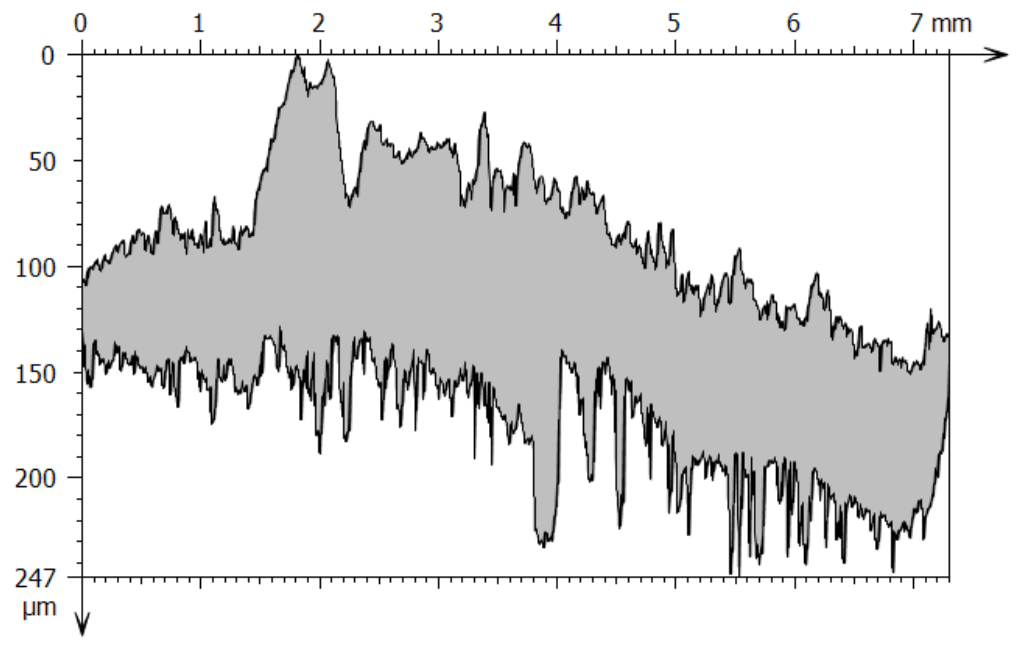

(b) Volume parameters - Extracted area

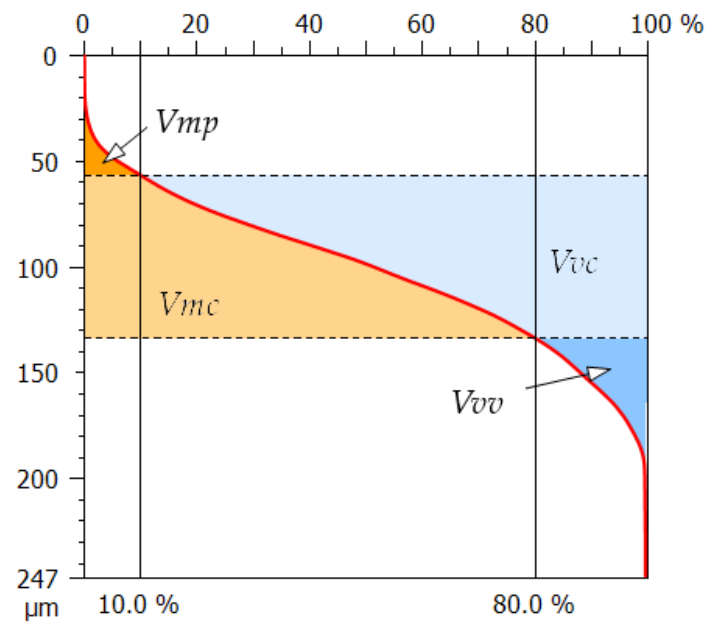

Figure 4. Graphical presentation of the functional (volume) parameters, for 10HNAP $(r=0)$ specimen: (a) series of surface profiles; (b) functional (volume) parameters of Abbott-Firestone curve according to ISO 25178.

\section{Results and Discussion}

\subsection{Measurement Results}

The results presented in this paper show measurements made for three materials (10HNAP, S355J2 and 2017-T4). Tests were carried out for bending and torsion and their combinations. The results presented the relationship between the surface topography parameters and the fractal dimension $D f$, including the $r$ parameter [45] defined by Equation (1).

A total of 99 specimens were investigated. In all, 30 measurements were taken for the 10HNAP material (see Figure 5a), 50 for the S355J2 material (see Figure 5c), and 19 for the 2017-T4 specimens (see Figure $5 b$ ). Table A1 containing the full set of data presented in the graphs is shown in Appendix A. 


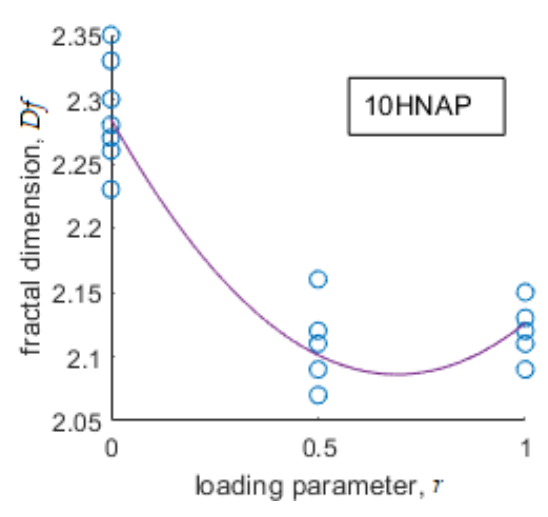

(a)

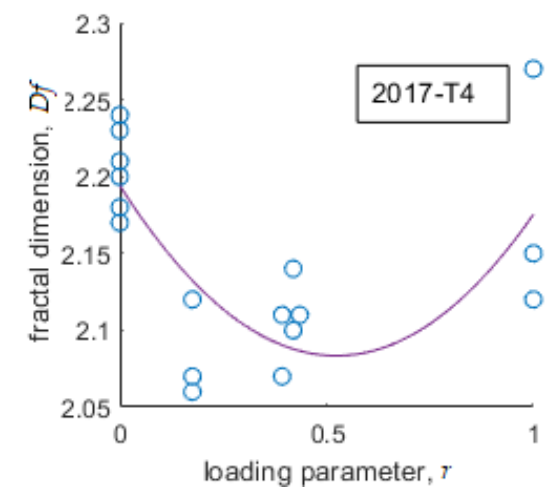

(b)

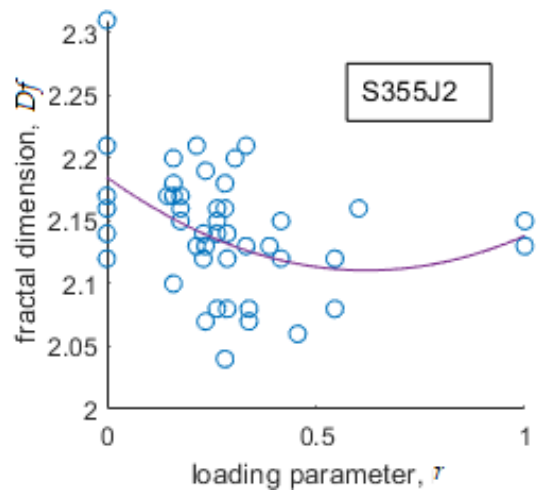

(c)

Figure 5. Fractal dimension $D f$ evaluation at different applied loading stress ratios of the $r$ parameter for the investigated materials: (a) 10HNAP steel, (b) 2017-T4 aluminium alloy, and (c) S355J2 steel.

The presented quadratic fitting was intended only to show the tendency of the change in the fractal dimension with respect to applied loading stress ratio $r$ parameter. On the basis of the presented fit, it would be completely unjustified to argue that this trend would make it possible to infer a fractal dimension $D f$.

Quadratic fits for all plots from Figure 6 are included. Based on the data set presented in this paper, it cannot be concluded that there is a simple correlation between the $S x$ and the load defined by the parameter $r$. The applied correlations were only an attempt to systematise the results and show the visual trend of the change in the areal surface parameters based on the quadratic function.

\subsection{Individual Fracture Zones}

In addition to measuring the entire fracture area with a $10 \times$ magnification, several measurements were taken at characteristic locations of the fatigue fracture (such as propagation and rupture areas) with a magnitude $100 \times$ and higher resolution. Examples of measurement results of three types of tested fracture surfaces are shown in Figure 7. Pseudo-photos of the fatigue fracture surface have been assembled and shown in the bottom and top of Figure 7, whereas the middle portions of Figure 7 are the 3D visualisations of the entire fracture areas. Maximum stresses occur on the surfaces of the specimens, making these spots future positions for fatigue crack initiation [46].

10HNAP V-notched specimens under fatigue bending (see Figure 7a) are characterised by symmetrical areas of propagation. The rupture zone is located in the centre of the fatigue fracture. The initiation site roughness for V-notched samples is slightly lower than in the same areas of other analysed samples after bending.

Similar to 10HNAP samples, the fractures of the S355J2 steel after fatigue bending have a symmetrical distribution of propagation areas and a rupture area in the central part of the fracture. The initiation site for these specimens is characterised by the highest roughness when compared to the 10HNAP and the 2017-T4.

2017A specimen fracture surface, presented in Figure 7c, consists of a few regions. The first one, situated near the notch, is the "propagation" zone, and around its centre is the initiation site. The second area, which we conventionally call the "rupture" area, is in the centre of the fracture characterised by typical tensile fracture. The third area is on the sides of the fracture, characterised by typical shear fracture, which is located at an angle with respect to the main fracture surface. 

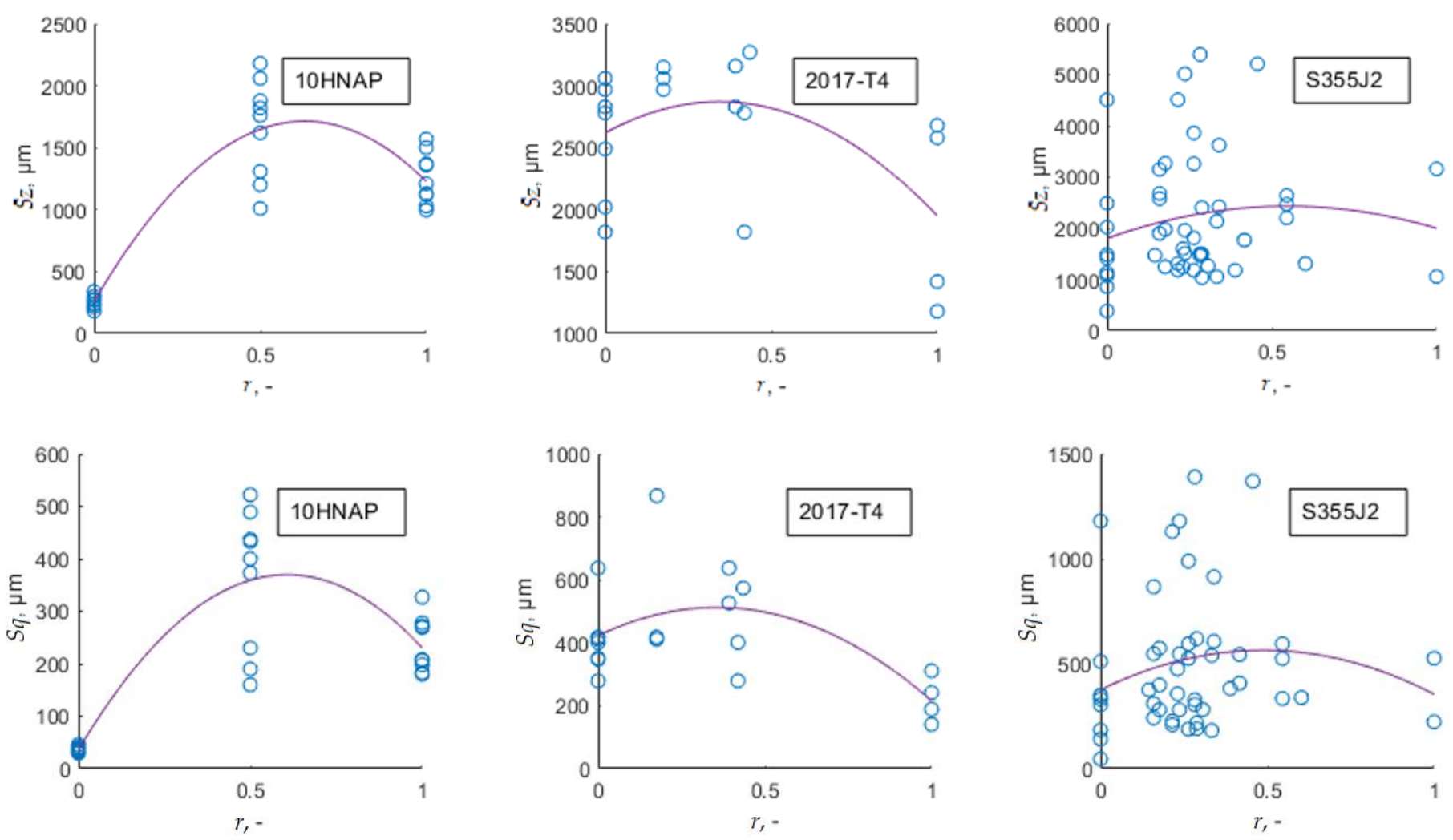

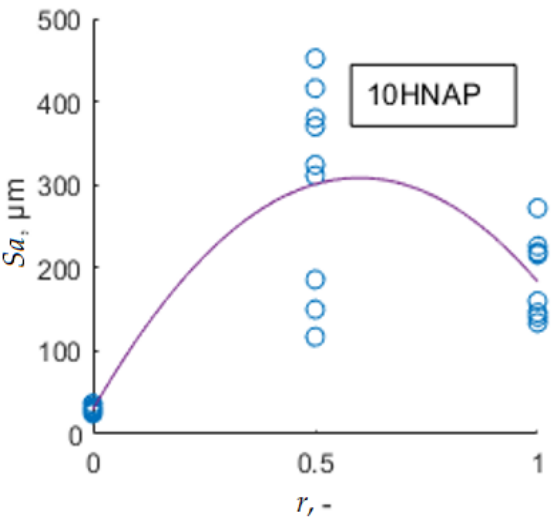

(a)

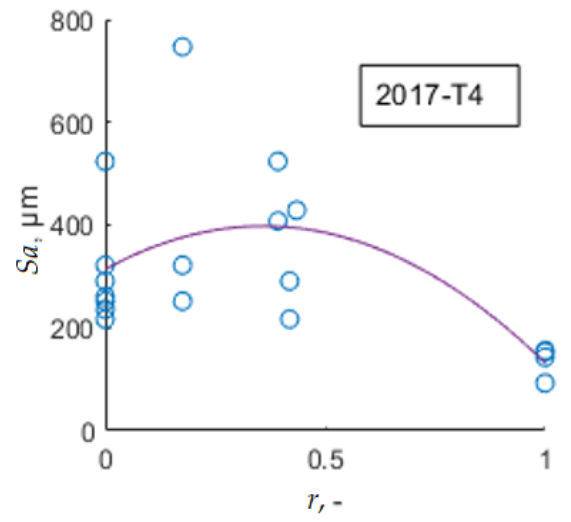

(b)

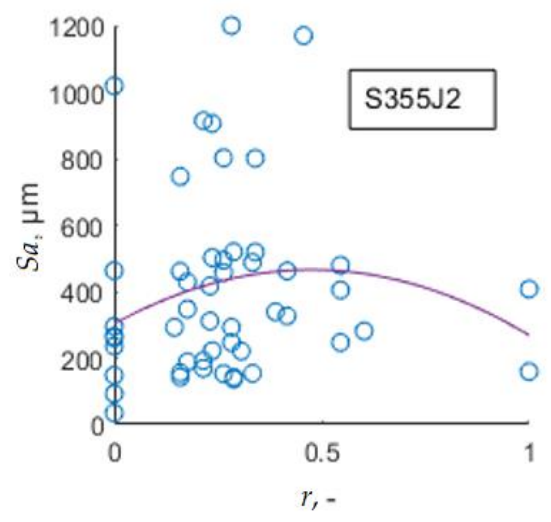

(c)

Figure 6. Areal surface parameters $S x(S z, S q, S a)$ evaluation at different applied loading stress ratios of the $r$ parameter for the investigated materials: (a) 10HNAP steel, (b) 2017-T4 aluminium alloy, and (c) S355J2 steel.

For the zones shown in Figure 7, the $D f$ values were measured and compared with their equivalents for the entire fracture ROI (see Table 2). For pure bending cases (10HNAP and 2017A), the highest value $D f$ was for the entire fracture surface. For the bending-torsion combination, it had the lowest result of $D f$. 


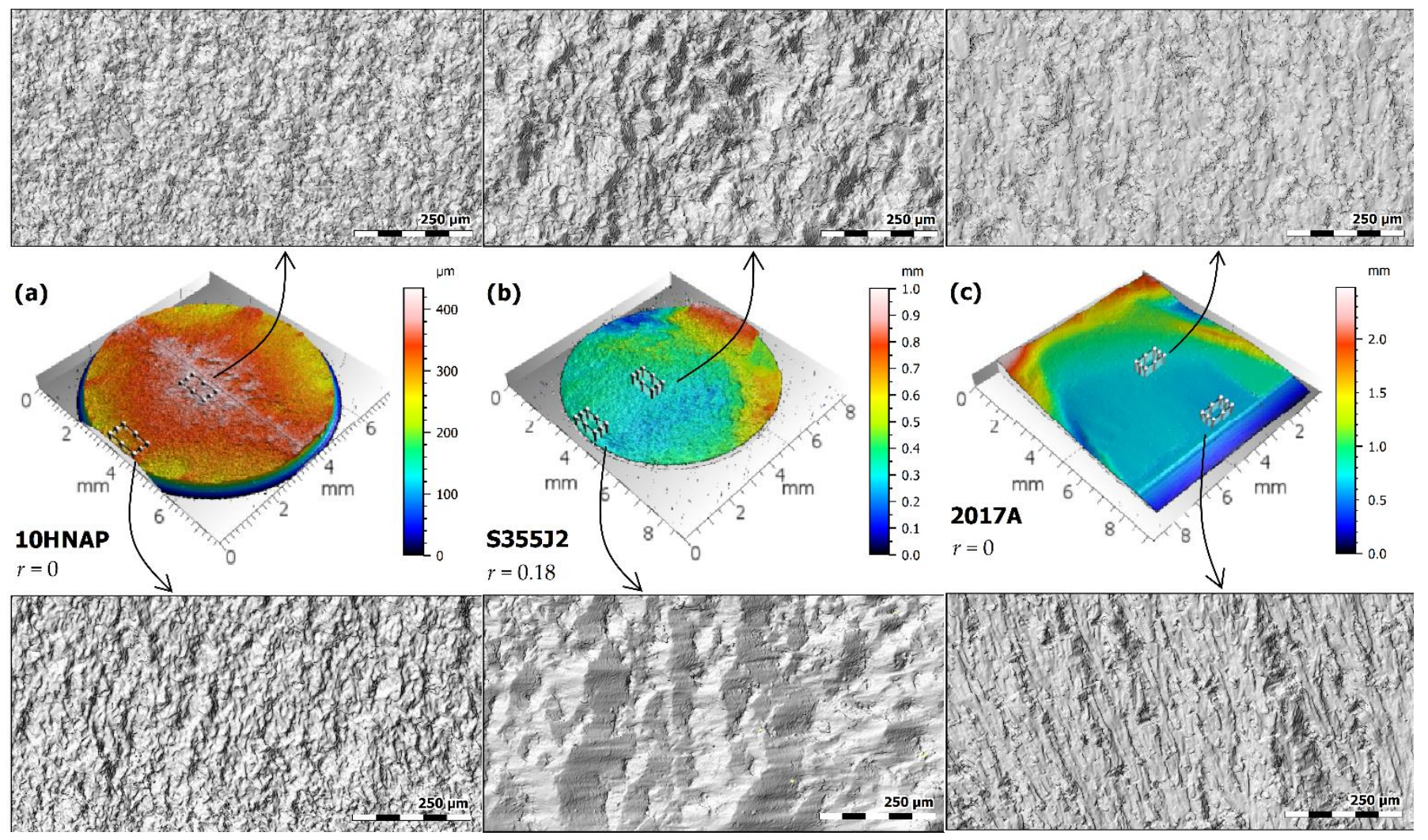

Figure 7. Exemplary fractures with marked spots of crack propagation of three analysed grades of specimens: (a) 10HNAP steel, (b) S355J2 steel, (c) 2017A-T4 aluminium alloy.

Table 2. Exemplary fractures fractal dimension $D f$ results for entire fracture and areas of crack initiation and propagation of three analysed types of specimens.

\begin{tabular}{cccc}
\hline Specimen & Entire Fracture & Initiation & Propagation \\
\hline 10HNAP $(r=0)$ & 2.280 & 2.230 & 2.224 \\
S355J2 $(r=0.18)$ & 2.170 & 2.088 & 2.176 \\
2017-T4 $(r=0)$ & 2.300 & 2.180 & 2.172 \\
\hline
\end{tabular}

A dissimilarity in granularity and coarseness of the fractures can be noticed. For uniaxially loaded specimens, the surface texture is fine-grained in the propagation area and in the rupture area. However, for specimens fatigued by combined bending-torsion, there are meaningful dissimilarities between these areas. In the propagation area, larger differences in material grain are apparent, as is their directionality, which is demonstrated by elongated grains. At the rupture area, this ceases to be visible.

There is a significant difference in the developments of the front side fracture surface caused by the shape of notch or lack thereof. For the circumferential or one-side V-notch configurations, notch effects occur at the early moment of crack growth. Nevertheless, as the crack extends, this effect gradually disappears, leading to total likeness of fracture surface topography. Therefore, it was selected to analyse data from the entire fracture surfaces, and areal parameters $S a, S z, S q$, and the fractal dimension $D f$ were chosen for the description of the topography.

\subsection{Statistical Dependencies of Fractal Dimensions}

Figure 8 presents the obtained distribution of the loading stress ratio $r$ parameter and the fractal dimension $D f$ values. 


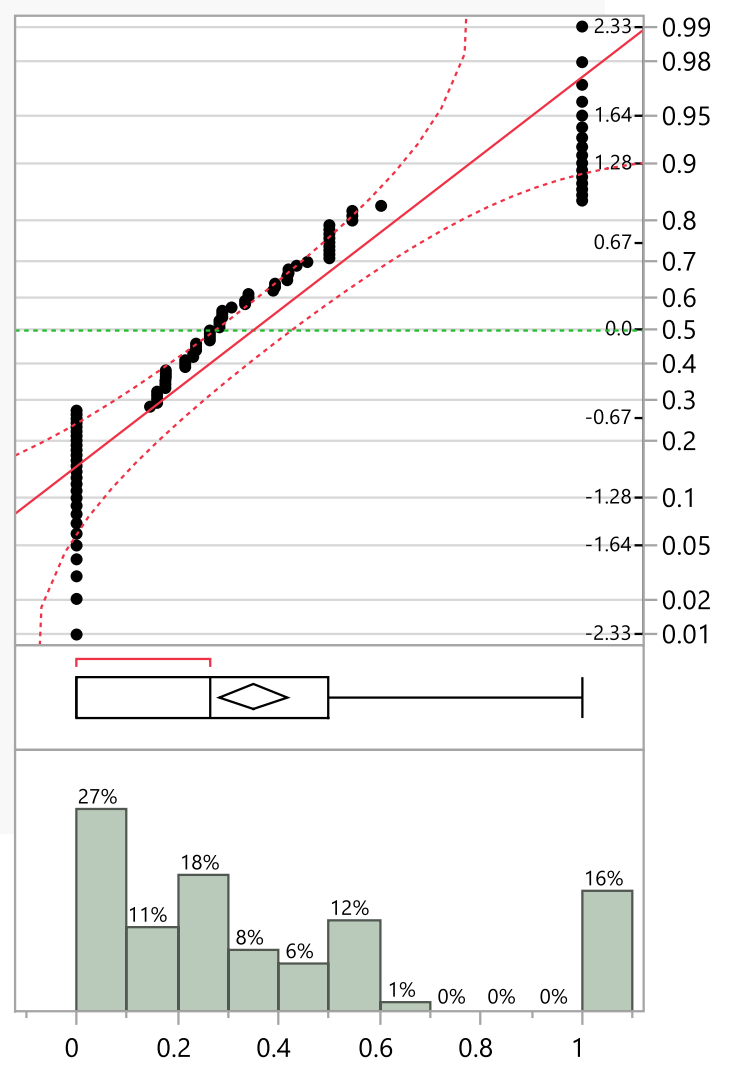

(a)

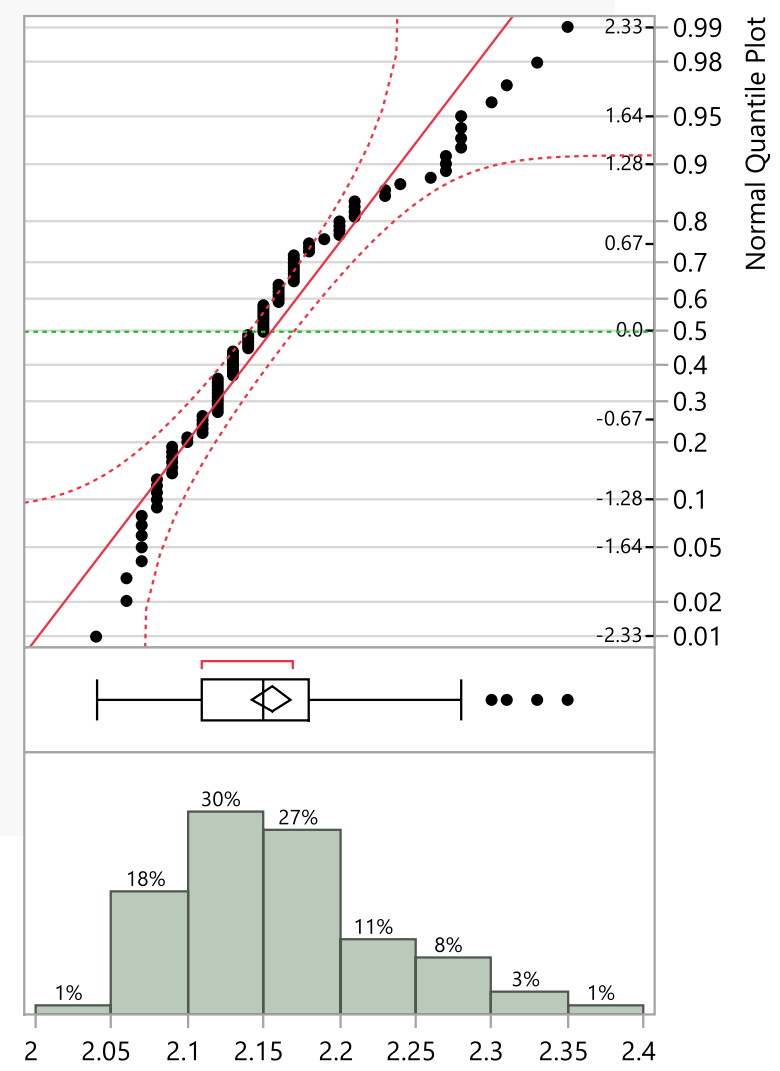

(b)

Figure 8. Distribution of: (a) $r$ parameter; and (b) fractal dimension $D f$.

The $y$-axis in range zero to one shows the empirical cumulative probability for each value, and the second y-axis shows the normal quantile scale. The dashed red line shows the Lilliefors confidence bounds [47], while the x-axis shows the column values.

The most, i.e., $27 \%$ of all samples, were specimens after pure bending $(r=0)$. On the other hand, the most common range of fractal dimension values was $D f=2.10-2.15$ and amounted to $30 \%$ of the population.

The greatest asymmetry between pure bending and pure torsion occurs for the ringnotched 10HNAP specimens. This is presented visually in Figure 9, where average values (see $x$ markers), 25th and 75th percentiles, including the median (see blue rectangles) and the most extreme data points (whiskers) of $D f$, are displayed at appropriate loading levels.

The averaged fractal dimensions for bending, torsion and bending-torsion are shown in Table 3.

Table 3. Averaged fractal dimension for bending (B), torsion (T) and bending-torsion (B-T).

\begin{tabular}{cccc}
\hline \multirow{2}{*}{ Loading Mode } & \multicolumn{3}{c}{ Averaged Fractal Dimension } \\
\cline { 2 - 4 } & 10HNAP & 2017-T4 & S355J2 \\
\hline Bending (B) & 2.28 & 2.20 & 2.18 \\
Torsion (T) & 2.13 & 2.17 & 2.14 \\
Bending-Torsion (B-T) & 2.10 & 2.10 & 2.13 \\
\hline
\end{tabular}



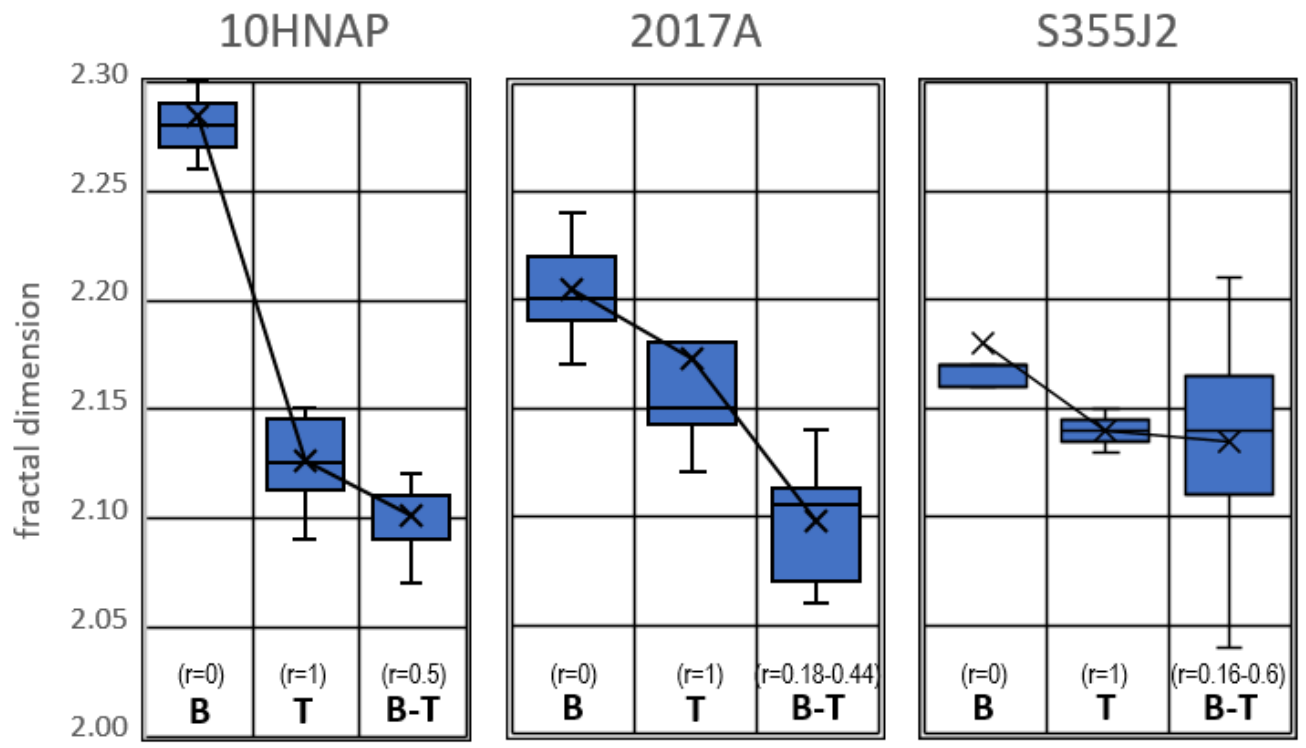

Figure 9. Fatigue fracture surface topographies averaged values for fractal dimension $D f$ for three case by case basis loading modes (B-bending; $\mathrm{T}$-torsion; B-T-bending-torsion). Adapted from [37].

For $10 \mathrm{HNAP}$, the average value of $D f$ for pure bending is $8.7 \%$ higher than that for load combinations, and $7.5 \%$ more than that for pure torsion, which indicates the highest sensitivity of the $D f$ parameter for pure bending in ring-notched specimens. The same trend occurs for the 2017-T4 alloy, where the average value of $D f$ for pure bending is $4.8 \%$ higher than that for load combinations, and $1.4 \%$ more than that for pure torsion. For the S355J2 steel, these values were equal to $2.3 \%$ and $1.9 \%$, respectively.

For comparison purposes, as shown in Figure 10, the arithmetical mean height, $\mathrm{Sa}$, has a different tendency, which may be due to the influence of the geometric discontinuities such as notches. In terms of the independence of the surface parameter from the loading conditions and the sample geometry, the fractal dimension $D f$ parameter seems to be more universal. A list of the maximum and minimum values of fractal dimension $D f$ and the arithmetical mean height $S a$ for the total fracture area is presented in Table 4.
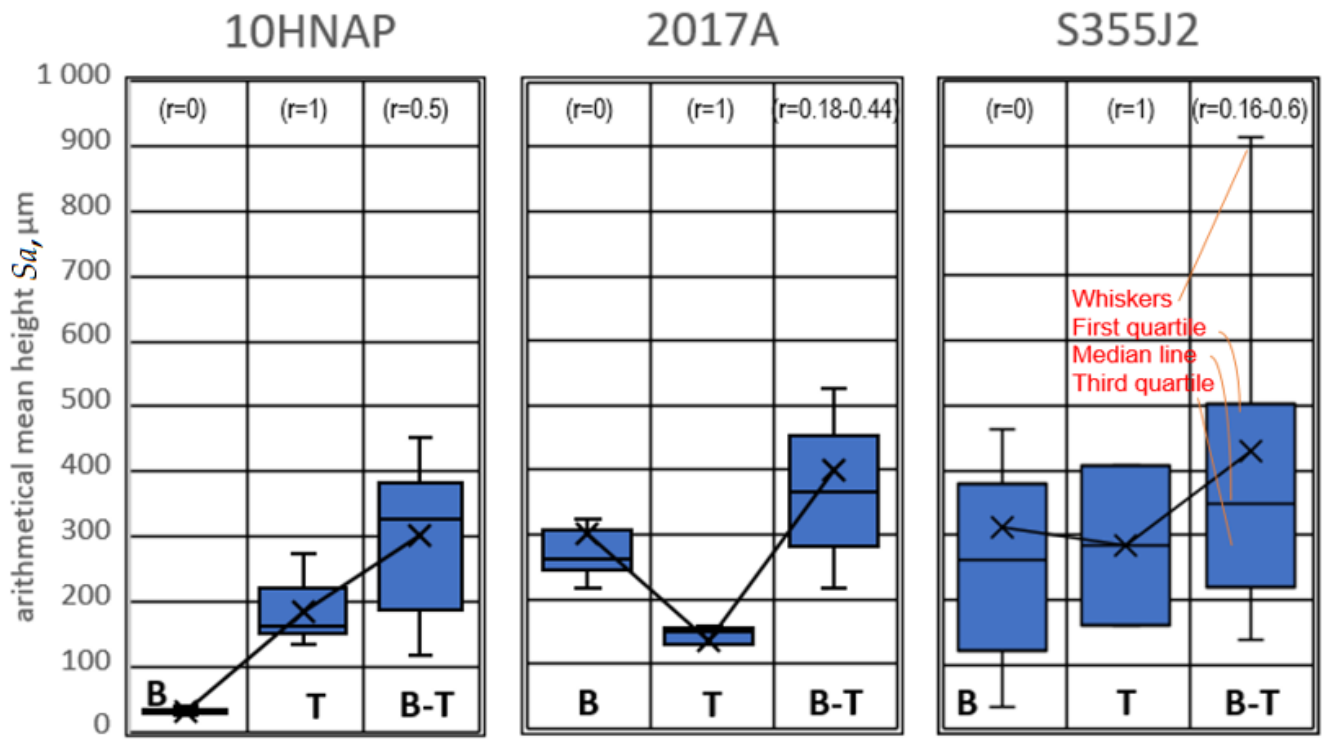

Figure 10. Specimen fracture surfaces averaged values for arithmetical mean height $S a$. 
Table 4. Extremum values of topography parameters for total fracture area.

\begin{tabular}{cccc}
\hline \multirow{2}{*}{ Parameter } & & Specimen & \\
\cline { 2 - 4 } & 10HNAP & 2017-T4 & S355J2 \\
\hline Df max. & $\mathrm{B}$ & $\mathrm{B}$ & $\mathrm{B}$ \\
Df $\min$. & $\mathrm{B}-\mathrm{T}$ & $\mathrm{B}-\mathrm{T}$ & $\mathrm{B}-\mathrm{T}$ \\
Sa $\max$. & $\mathrm{B}-\mathrm{T}$ & $\mathrm{B}-\mathrm{T}$ & $\mathrm{B}-\mathrm{T}$ \\
Sa $\min$. & $\mathrm{B}$ & $\mathrm{T}$ & $\mathrm{T}$ \\
\hline
\end{tabular}

\subsection{Fracture Surface Parameters for Extremal Fractal Dimensions Cases}

The objectives of this section are to compare the standard surface parameters and specify their sensitivity to directionality of fracture for extremal fractal dimensions $D f$ for the three tested materials. For this purpose, in addition to a isometric view of the fractures, the study of the texture direction and the Abbott-Firestone curve are presented (see Figure 11). In Figure 12, the basic results for volume and $S k$ parameters are presented in tabular forms and graphs, to complement the data. In detail, the texture direction graph (see Figure 11-in the lower left corners) analyses the topography using the Fourier transformation and shows the dominant surface directions on a polar plot. It presents the three dominant directions of the topography. Abbott-Firestone curves (see Figure 11-lower right corners) are connected to the distribution of heights and its cumulated curve. Core height $S k$ (see Figure 12-right sides) represents the distance between the highest and lowest level of the core surface. The left side of Figure 12 shows the ISO 25178 functional volume parameters that are calculated with respect to it: $V m p$ (peak material volume), $V m c$ (core material volume), $V v c$ (core void volume), $V v v$ (valley void volume), and $V m p, V m c, V v v$ zones, respectively.

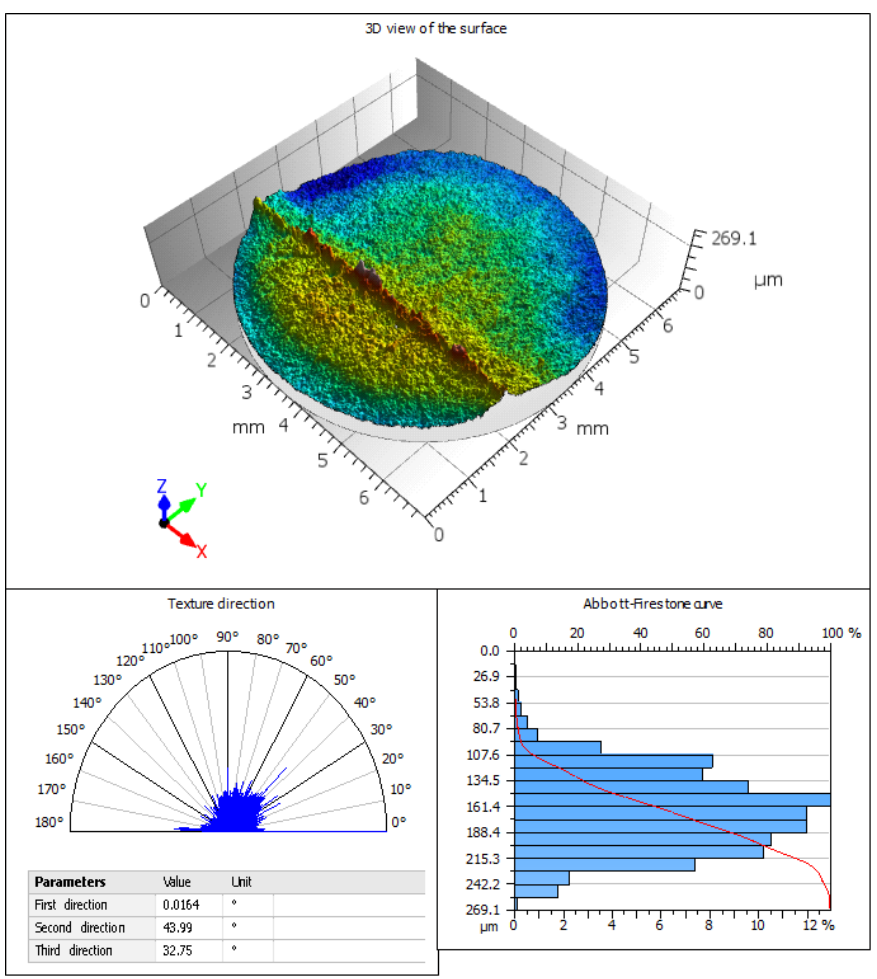

(a)

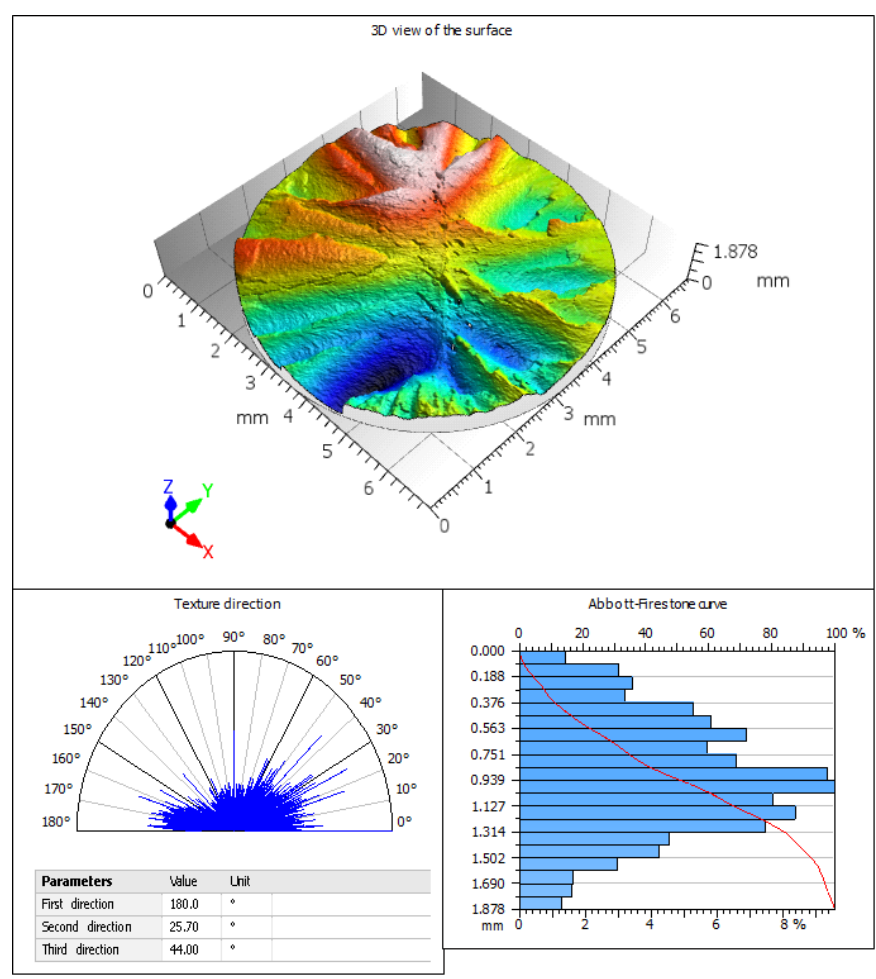

(b)

Figure 11. Cont. 


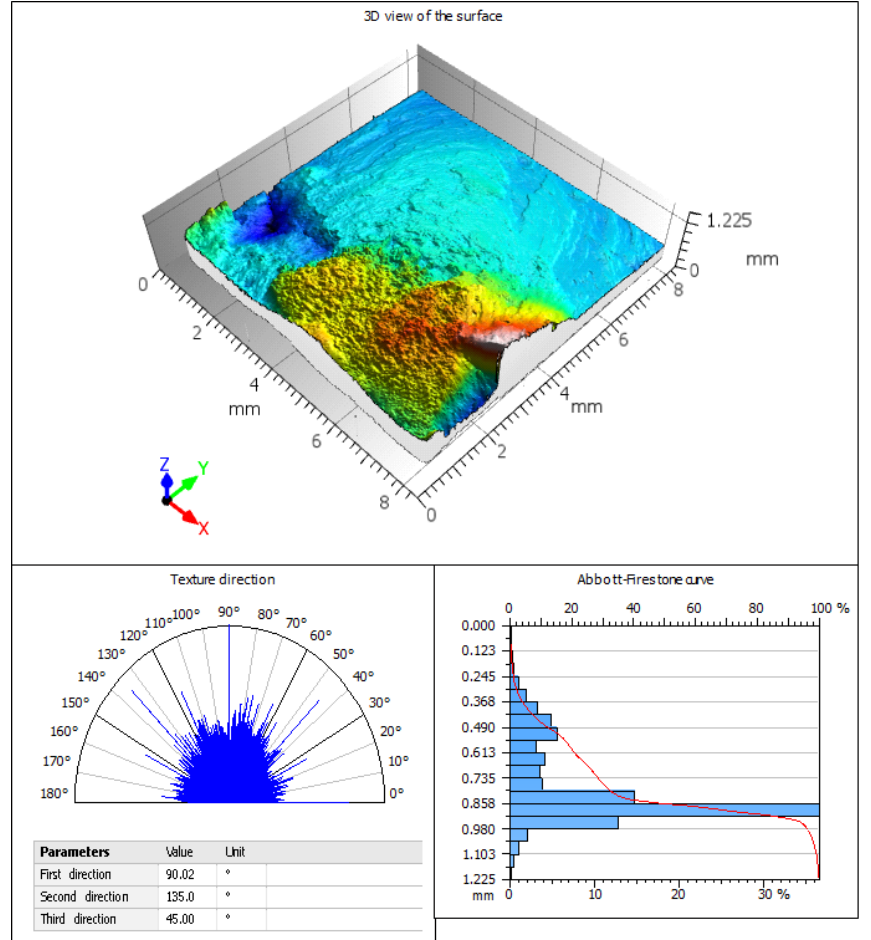

(c)

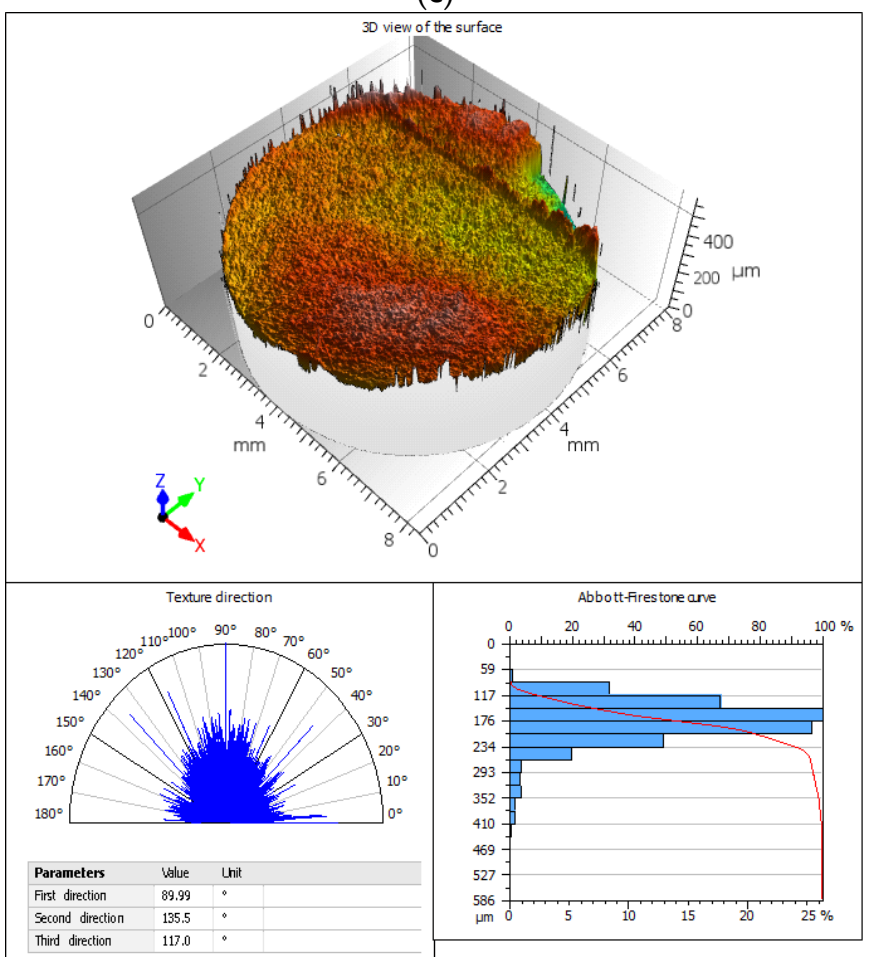

(e)

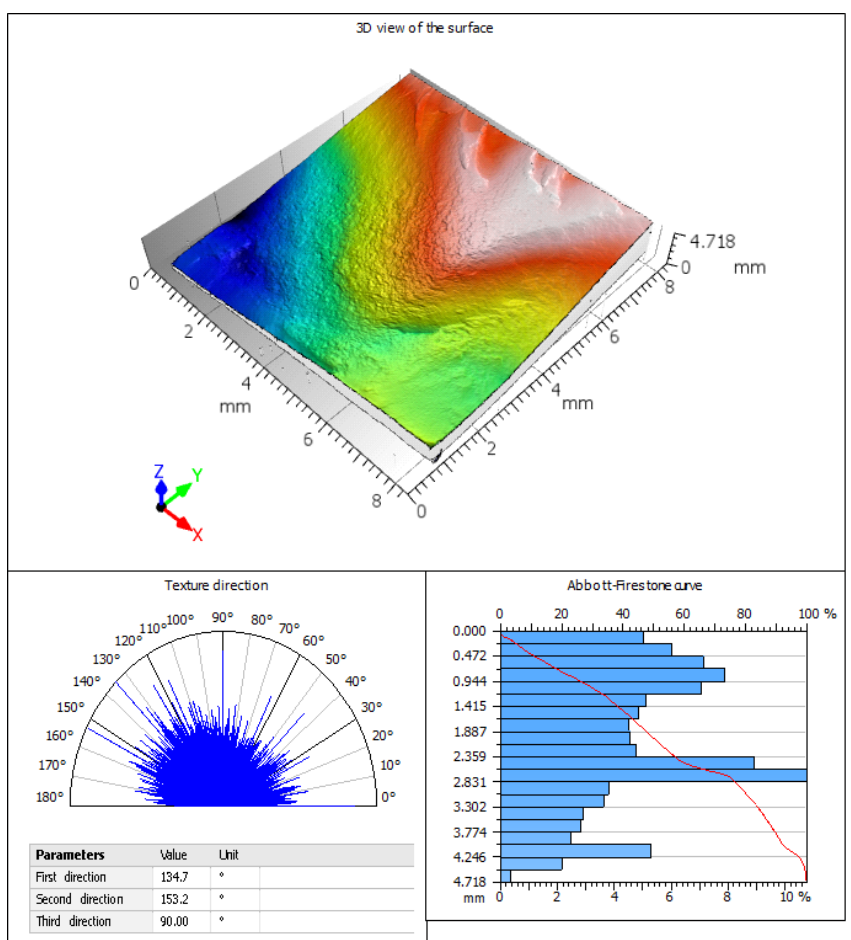

(d)

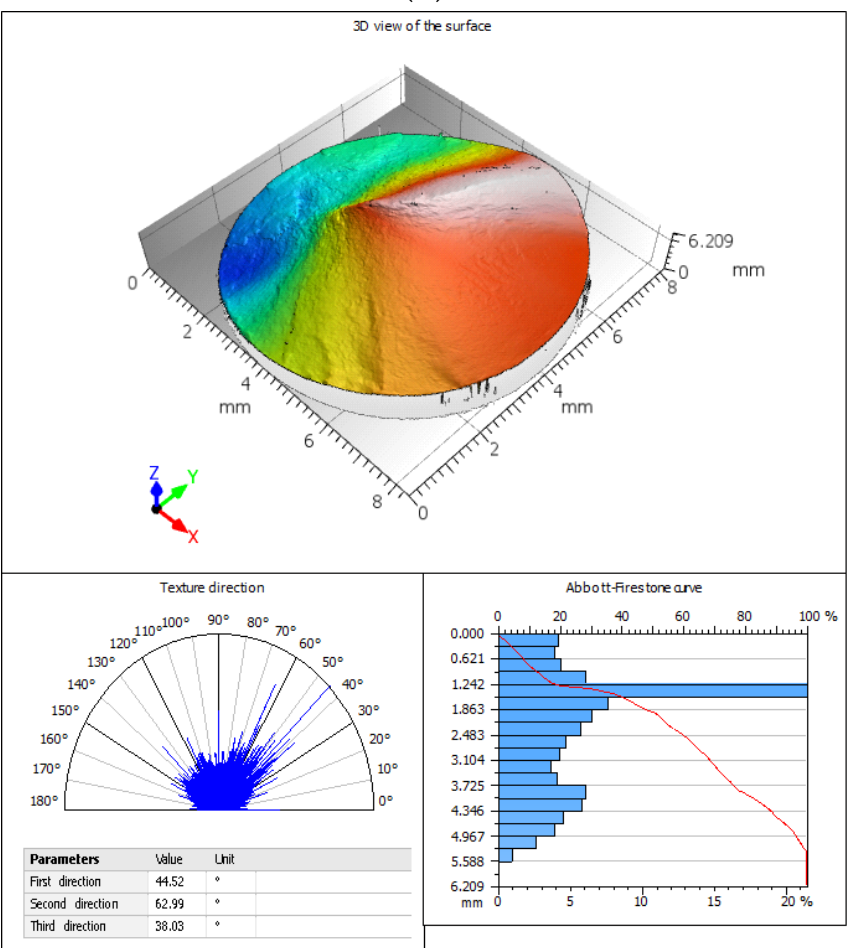

(f)

Figure 11. Fractures extremal $D f$ values for: (a) max. 10HNAP; (b) min. 10HNAP; (c) max. 2017-T4; (d) min. 2017-T4; (e) $\max . \mathrm{S} 355 \mathrm{~J} 2$; (f) $\min . \mathrm{S} 355 \mathrm{~J} 2$. 


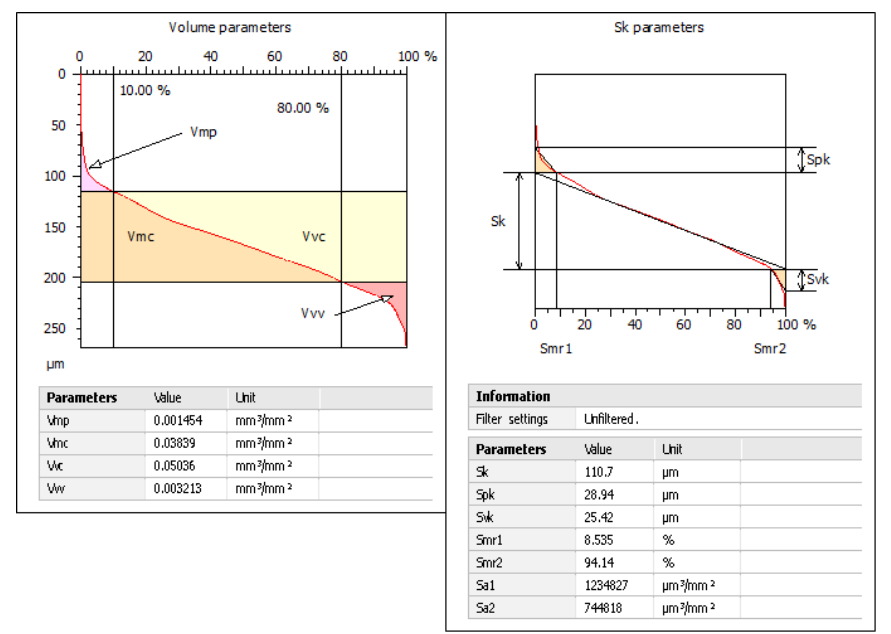

(a)

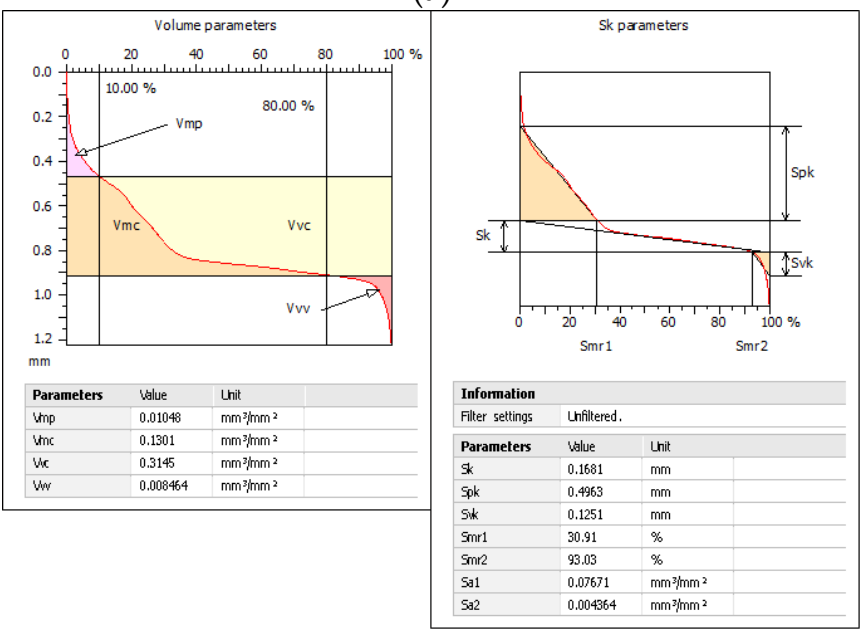

(c)

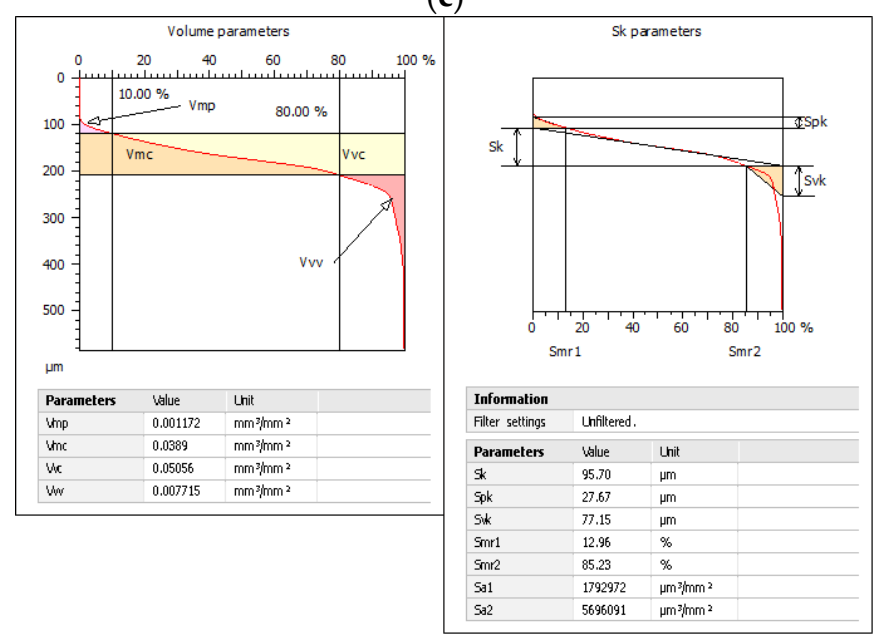

(e)

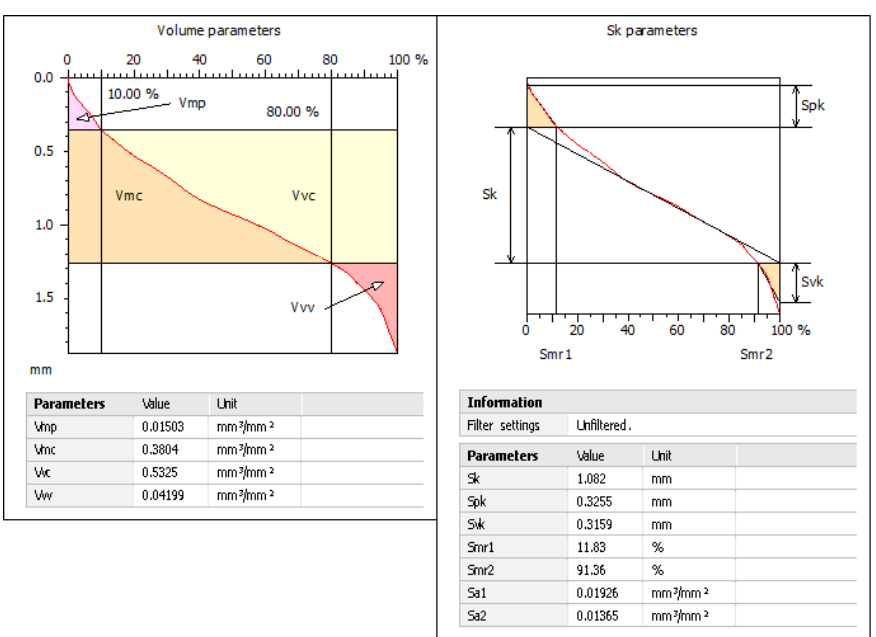

(b)

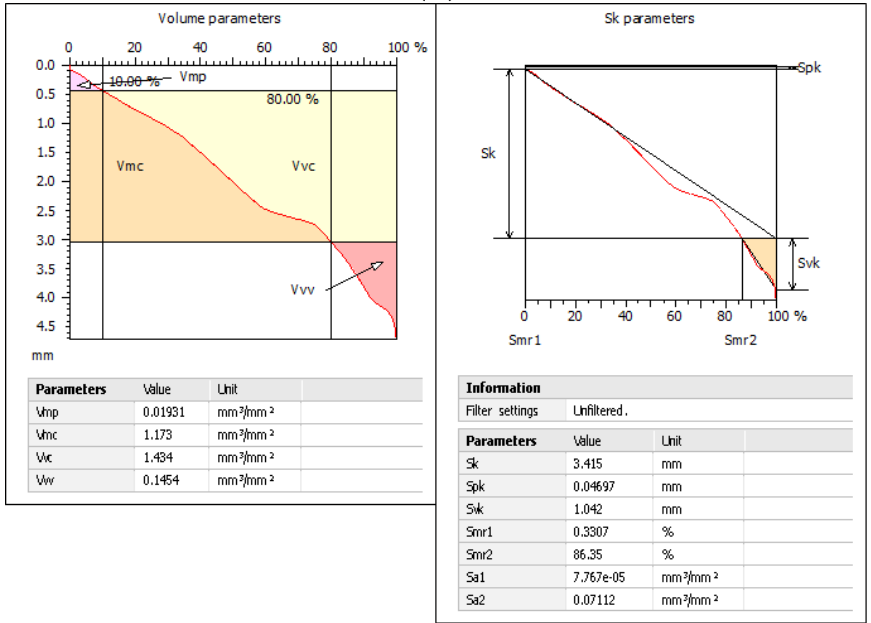

(d)

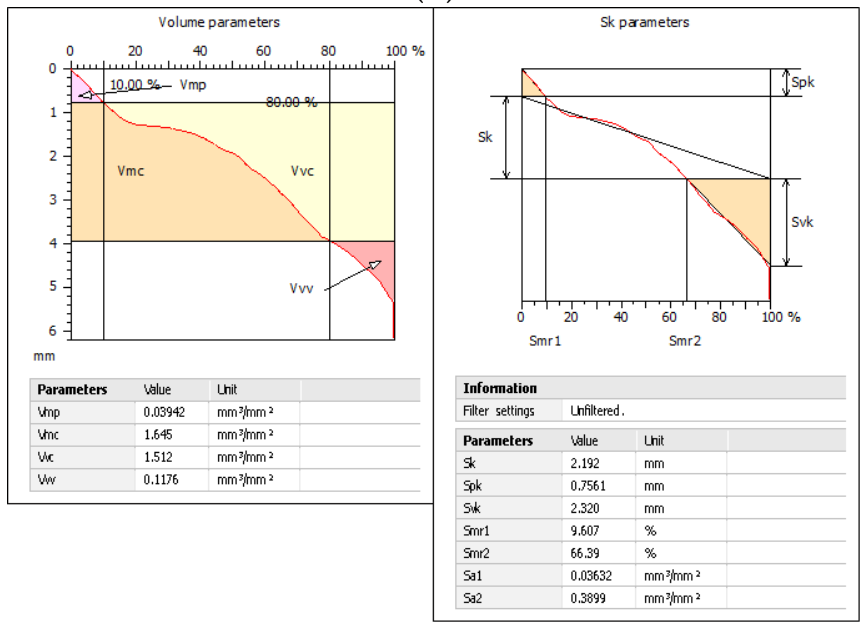

(f)

Figure 12. Volume and $S k$ parameters of fracture extremal $D f$ values for: (a) max. 10HNAP; (b) min. 10HNAP; (c) max. 2017-T4; (d) min. 2017-T4; (e) max. S355J2; (f) min. S355J2.

In general, regarding the texture direction for minimum $D f$, the distribution of directions is more extensive for all three sample types. As for the Abbott-Firestone plot, the minimum values of the fractal dimension $D f$ for all materials tested results in histogram distribution that is more even. This causes the Abbott-Firestone curve for maximum $D f$ val- 
ues to be more curved at extreme heights. Moreover, the minimum $D f$ is characterised by a more rectilinear Abbott-Firestone curve. On the Abbott-Firestone curve, the cases with the smallest $D f$ values are characterised by much higher values of height distribution compared to the maximum values of the fractional dimensions $D f$ of the other analysed cases.

In the case of volume parameters (left sides in Figure 12), the maximum $D f$ values are characterised by much thinner $V m c$ and $V v c$ stripes (in shades of brown). This relationship is presented in Figure 12a, where minimum $V v c$ is $991 \%$ higher than its maximum value for the 10HNAP steel. The S355J2 and 2017A samples also reveal significant differences, of $4229 \%$ and $902 \%$, respectively.

In addition, the curve (identical to the Abbott-Firestone curve shown in Figure 11) is steeper at the edge of the plot for $V m p$ and $V v v$. The maximum $D f$ cases also have significantly smaller height ranges.

$S k$ parameters are characterised by much larger values in the case of minimal fractal dimensions $D f$. This difference is especially visible in Figure 13b. There are very clear differences in core height $S k$ between the minimum and maximum values of the fractal dimension $D f$, respectively $977 \%$ for the $10 \mathrm{HNAP}, 2290 \%$ for the S355J2 and $2032 \%$ for the 2017-T4 samples.
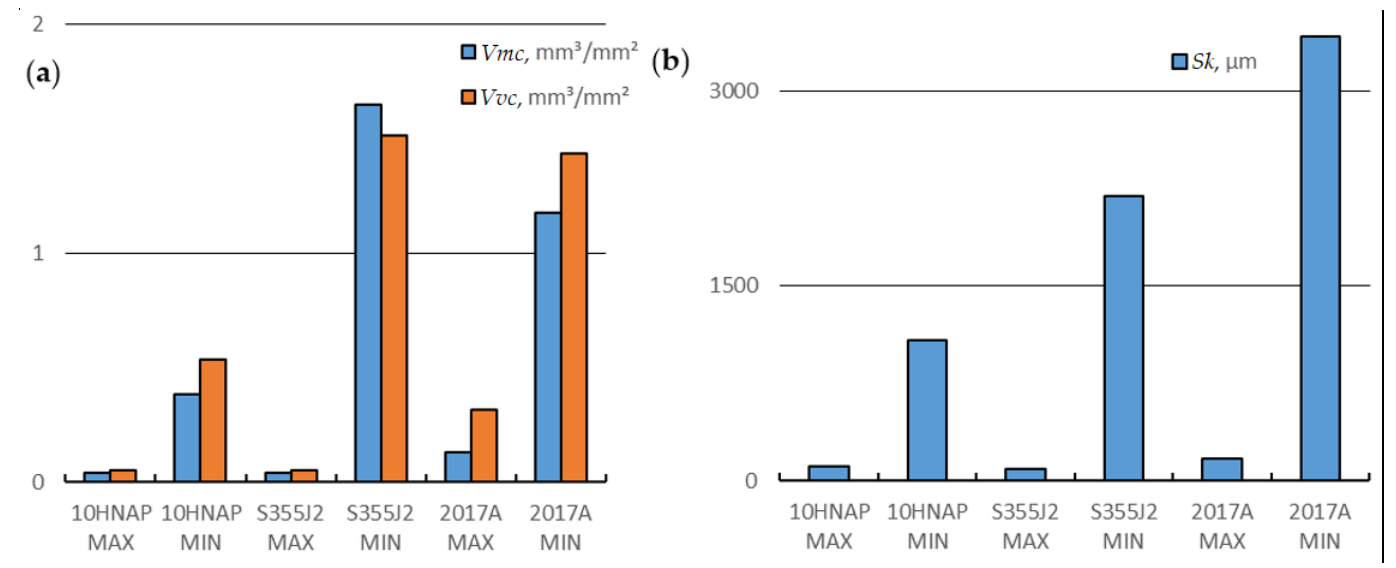

Figure 13. Fracture surface properties ((a) $V m c$ and $V v c ;(\mathbf{b}) S k)$ for extremal fractal dimension cases.

\subsection{Relationship between Df and Areal Surface Parameters}

Figure 14 shows the aggregate plots containing data from all 99 specimens analysed, demonstrating the correlation between $D f$, and $S q, S a, S z$, respectively. Linear fitting was applied to all data. Mean values have also been plotted. For all cases, the linear fitting coefficient of determination $R^{2}$ took similar values of around 0.24 .
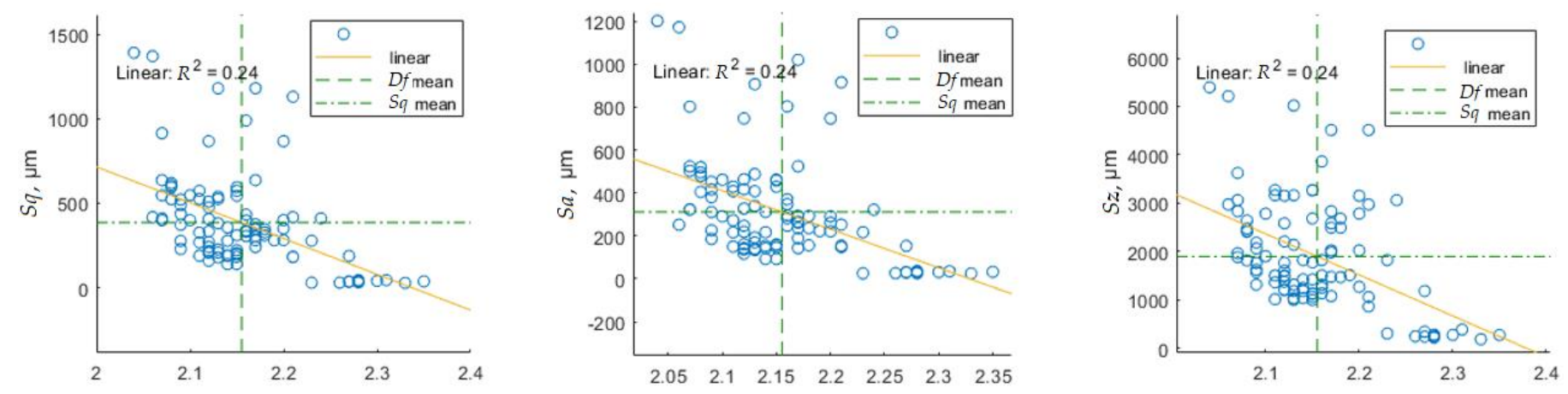

Figure 14. Relationship between areal surface parameters $S x$ and fractal dimension $D f$ values.

Different regression neural network models were compared using Regression Learner App by Matlab software (R2021b version, Mathworks, Natick, MA, USA) and the trained 
models were exported to a workspace to make predictions for the data. In order to find the optimal $S a$ model for $D f$, regardless of the sample type, these results were predicted and plotted in Figure 15 with Narrow Neural Network, and the test statistical results are displayed in Table 5. All features used in the model, before Principal Component Analysis (PCA), kept enough components to explain 95\% variance. Abbreviations MSE; MAE and RMSE stand for Mean Squared Error; Mean Absolute Error and Root Mean Square Error, respectively.

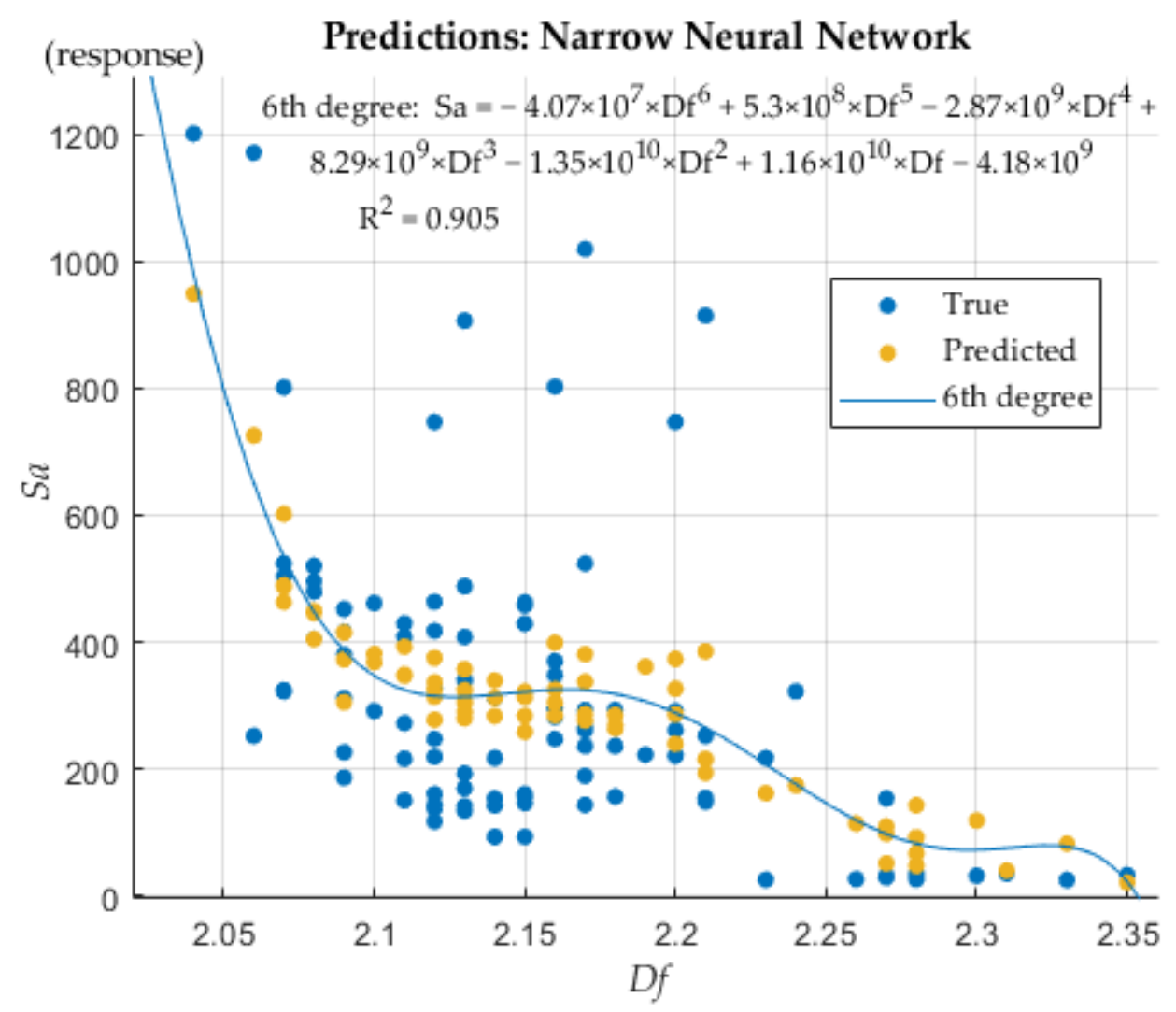

Figure 15. Response (Sa) vs. fractal dimension $D f$ Narrow Neural Network model and their 6th degree fit.

Table 5. The main statistical results of the Narrow Neural Network model.

\begin{tabular}{cccc}
\hline RMSE & $\boldsymbol{R}^{2}$ & MSE & MAE \\
\hline 202.66 & 0.31 & 41072 & 145.98 \\
\hline
\end{tabular}

After training, a model in Regression Learner (see Figure 15) predicted data were subjected to the basic fitting tool, for which the 6th degree type of fit turned out to be the best fit, for which $R^{2}=0.905$.

Finally, the thin-plate spline interpolant procedure was used to present the relation of $D f, S a$ and $r$ raw data, where $D f$ is normalised by mean 2.155 and standard deviation 0.06595 and where $S a$ is normalised by mean 311.5 and std amounting to 244.1 (see Figure 16). As can be seen, the fitted function is well defined for these parameters. For pure torsion $(r=1)$ (yellow zones) at a low level of $S a$ values were up to a maximum of $500 \mu \mathrm{m}$. 


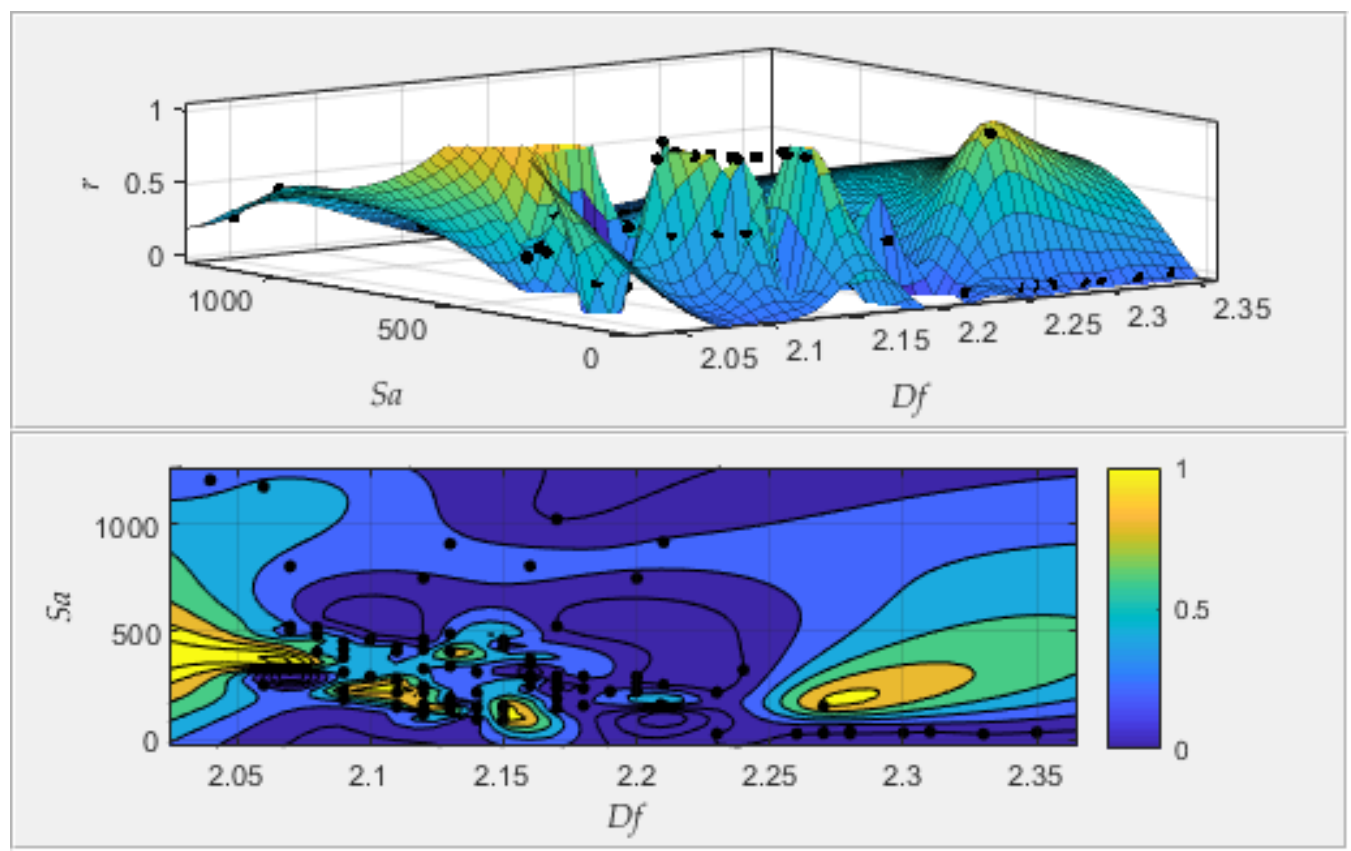

Figure 16. Relationship between $D f$, $S a$ and $r$ values.

\subsection{Material and Loading Model Based on Fracture Surface Topography}

To link the surface topography, represented by $D f$, with the material properties and, for instance, with sliding friction, several analyses were performed using, for example, the Weierstrass-Mandelbrot (W-M) function, as in the study [48]. However, in the analysed case, different materials and methods of loading were studied in order to find the universal parameter connected to the material features and loading ratios. For comparison with fractal dimension $D f$ regardless of the sample type, the new indicator called material and loading parameter $P$ were introduced.

$$
P=\frac{1}{S a}\left(\frac{E}{\sigma_{y}}+r+1\right)
$$

where: $E$ is the Young's modulus; $\sigma_{y}$ 一the Yield stress; and $r$ is the loading stress ratio.

The results of the material and loading parameter $P$ vs. fractal dimension $D f$ were plotted in Figure 17 with Gaussian fit, and the statistical results are displayed in Table 6. Prediction bounds indicate that there is a $95 \%$ chance that the new observation is actually contained within the lower and upper prediction bounds. The four (from 99) samples are outside the specified prediction bounds.

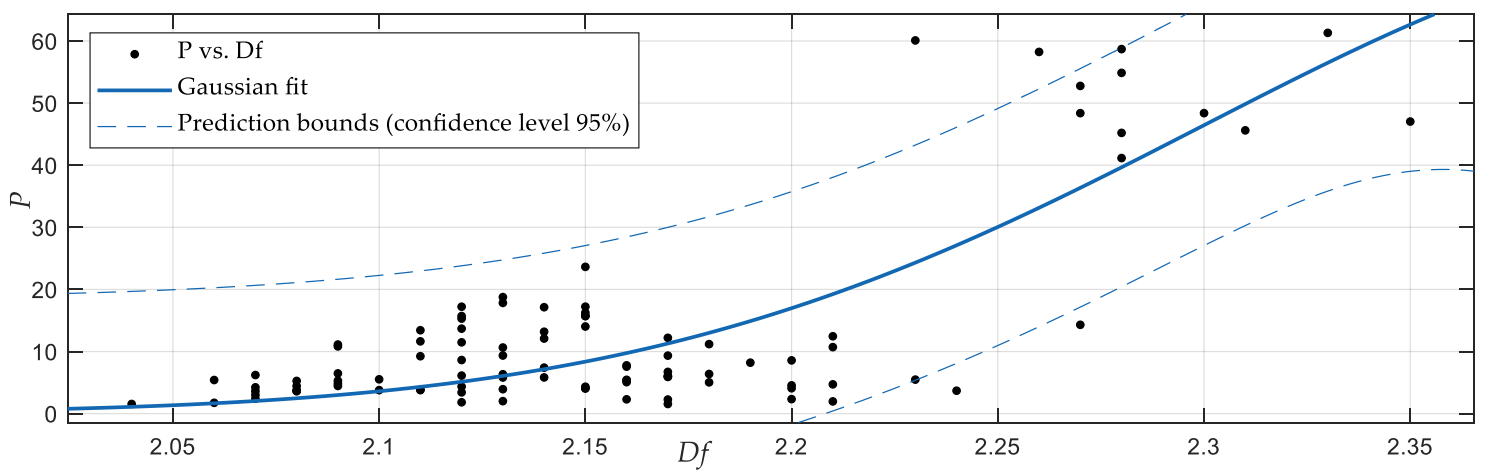

Figure 17. Material and loading parameter $P$ vs. fractal dimension $D f$ and their Gaussian fit. 
Table 6. Gaussian curve fitting model parameters for $P$ vs. $D f$.

\begin{tabular}{cc}
\hline Curve Fitting, General Model Gaussian & Goodness of Fit \\
\hline$f(x)=a \times \exp \left(-((x-b) / c)^{2}\right)$ & SSE: 8383 \\
Coefficients: & $R^{2}: 0.637$ \\
$a=76.3$ & Adjusted $R^{2}: 0.6294$ \\
$b=2.435$ & $R M S E: 9.345$ \\
$c=0.1918$ & \\
\hline
\end{tabular}

\section{Conclusions}

This paper is a systematic study of the relationship between the fracture surface geometry and the loading histories for components subjected to proportional and nonproportional bending-torsion loading, as well as pure bending and pure torsion. In addition, the paper considers aluminium alloys and construction and structural steels, as well as various $\mathrm{V}$-notched and smooth specimen geometries. The investigation was carried out via surface fractal dimension $D f$ and areal surface parameters $S a, S q$, $S z$ evaluated at total fracture fatigue surface area. It presents a means of carrying out post-failure estimation of the effect of the loading rate under bending-torsion fatigue. Investigation of the biaxialfatigued fracture in the context of fractal dimension $D f$ revealed that:

- $\quad$ For all investigated specimens, the largest values of $D f$ are for bending, slightly lower for torsion, and the smallest for combined loads;

- The size distribution of peaks and valleys is well described by the fractal theory;

- $\quad$ The highest sensitivity of the $D f$ parameter occurs for pure bending in ring-notched specimens;

- $\quad$ Surface topography parameter values such as areal parameters $S x$, volume parameters $V x$ and core height parameter $S k$ are significantly inversely related to the fractal dimension $D f$;

- Using Narrow Neural Network, it has been found a 6th degree type model, with the best fit arithmetical mean height $S a$ to fractal dimension $D f$, with a coefficient of determination $R^{2}$ equal to 0.905 ;

- The obtained results show that the fracture surface topography is a function of the loading condition, which affects the fracture mechanisms;

- Material and loading parameter $P$ shows a rather good fit to fractal dimension $D f$, with $R^{2}=0.637$, but different loading methods and materials still cause some discrepancies;

- The fractal dimension analysis of the total area method can be extended to other materials under bending-torsion fatigue;

- The presented results indicate that using only fractal dimension $D f$ in a function of $r$ is an inaccurate approach to clearly analyse the conditions under which the specimen was damaged. It should be mentioned that, apart from the $r$ parameter other factors have an important impact on the fatigue crack mechanisms. However, the fracture surface morphology recaptures important stages of the fatigue crack process. Fractal dimension, in connection with other ratios of fractography, can be an effective tool for comprehensive failure analysis;

- $\quad$ The proposed method can be applied to the prediction of fracture behaviour and the cracking process in cases dependent on the loading conditions and features of the material.

Funding: This research received no external funding.

Data Availability Statement: Data presented in this article are available at request from the author.

Acknowledgments: The author kindly acknowledges Henryk Achtelik, Zbigniew Marciniak and Sebastian Faszynka for sharing their specimens after fatigue tests: 10HNAP, S355J2 steels and 2017-T4 aluminium alloy, respectively.

Conflicts of Interest: The author declare no conflict of interest. 


\section{Nomenclature}

\begin{tabular}{|c|c|}
\hline$D_{f}$ & - \\
\hline$E$ & GPa \\
\hline$P$ & $1 / \mathrm{mm}$ \\
\hline$r$ & - \\
\hline$R$ & - \\
\hline$R^{2}$ & - \\
\hline$S a$ & $\mu \mathrm{m}$ \\
\hline$S k$ & $\mu \mathrm{m}$ \\
\hline Smr1, Smr2 & $\%$ \\
\hline$S p$ & $\mu \mathrm{m}$ \\
\hline Spk & $\mu \mathrm{m}$ \\
\hline$S q$ & $\mu \mathrm{m}$ \\
\hline Sv & $\mu \mathrm{m}$ \\
\hline Svk & $\mu \mathrm{m}$ \\
\hline$S z$ & $\mu \mathrm{m}$ \\
\hline$V m c$ & $\mathrm{~mm}^{3} / \mathrm{mm}^{2}$ \\
\hline$V m p$ & $\mathrm{~mm}^{3} / \mathrm{mm}^{2}$ \\
\hline$V v c$ & $\mathrm{~mm}^{3} / \mathrm{mm}^{2}$ \\
\hline$V v v$ & $\mathrm{~mm}^{3} / \mathrm{mm}^{2}$ \\
\hline$\sigma_{\max }$ & $\mathrm{MPa}$ \\
\hline$\sigma_{y}$ & $\mathrm{MPa}$ \\
\hline$\tau_{\max }$ & $\mathrm{MPa}$ \\
\hline MSE & - \\
\hline$M A E$ & - \\
\hline$P C A$ & - \\
\hline RMSE & - \\
\hline
\end{tabular}

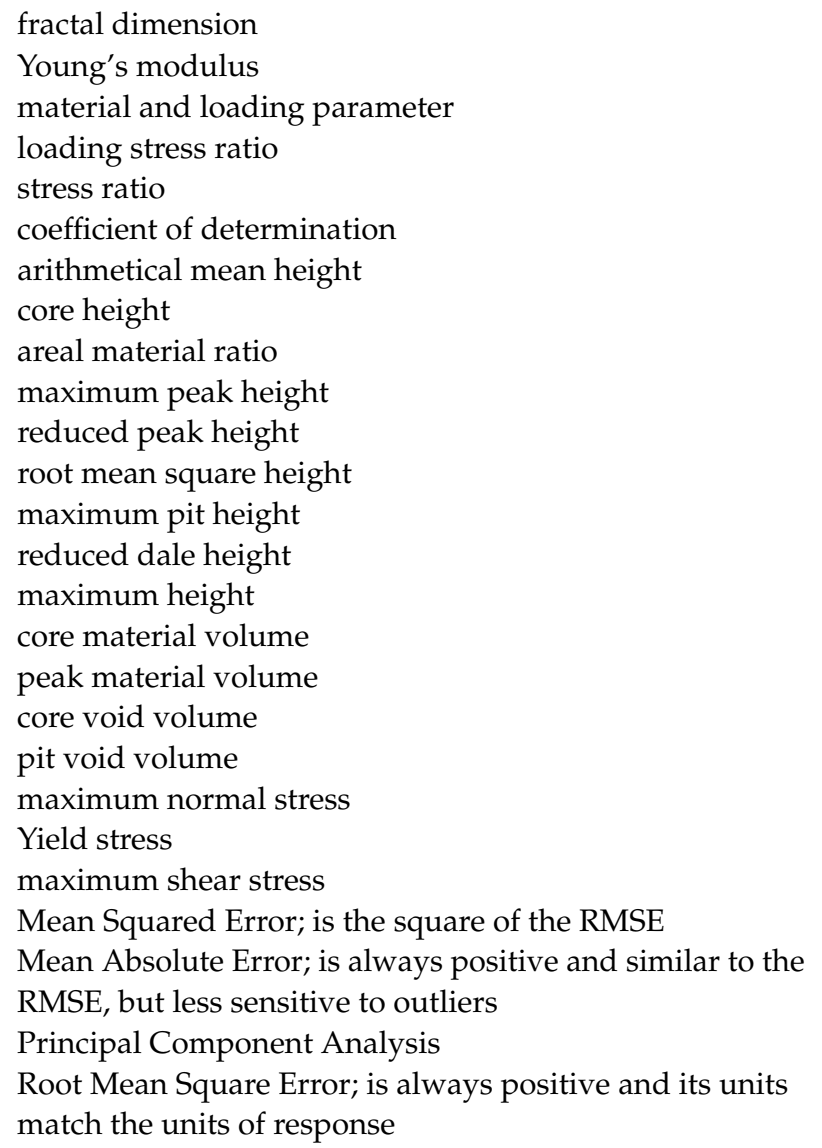

\section{Appendix A}

Table A1. Fractal dimension $D f$ and areal surface $S x$ parameters versus loading stress ratio $r$ for the studied materials.

\begin{tabular}{cccccccccccccccc}
\hline & 10HNAP Steel & \multicolumn{1}{c}{ 2017-T4 Aluminium Alloy } & \multicolumn{4}{c}{ S355J2 Steel } \\
\hline $\boldsymbol{D} \boldsymbol{f}$ & $\boldsymbol{S} \boldsymbol{q}$ & $\boldsymbol{S} \boldsymbol{z}$ & $\boldsymbol{S a}$ & $\boldsymbol{r}$ & $\boldsymbol{D} \boldsymbol{f}$ & $\boldsymbol{S} \boldsymbol{q}$ & $\boldsymbol{S} \boldsymbol{z}$ & $\boldsymbol{S a}$ & $\boldsymbol{r}$ & $\boldsymbol{D} \boldsymbol{f}$ & $\boldsymbol{S} \boldsymbol{q}$ & $\boldsymbol{S} \boldsymbol{z}$ & $\boldsymbol{S a}$ & $\boldsymbol{r}$ \\
\hline 2.28 & 34 & 216 & 28 & 0.00 & 2.18 & 347 & 2490 & 236 & 0.00 & 2.16 & 332 & 1133 & 295 & 0.00 \\
2.27 & 35 & 236 & 29 & 0.00 & 2.20 & 351 & 2020 & 261 & 0.00 & 2.21 & 185 & 859 & 148 & 0.00 \\
2.23 & 31 & 301 & 25 & 0.00 & 2.23 & 279 & 1820 & 217 & 0.00 & 2.31 & 46 & 383 & 35 & 0.00 \\
2.27 & 39 & 341 & 31 & 0.00 & 2.21 & 418 & 2970 & 252 & 0.00 & 2.17 & 305 & 1073 & 266 & 0.00 \\
2.28 & 39 & 236 & 34 & 0.00 & 2.17 & 637 & 2830 & 524 & 0.00 & 2.12 & 510 & 1483 & 463 & 0.00 \\
2.28 & 32 & 276 & 26 & 0.00 & 2.20 & 401 & 2780 & 291 & 0.00 & 2.17 & 1180 & 4510 & 1020 & 0.00 \\
2.33 & 29 & 182 & 25 & 0.00 & 2.24 & 411 & 3060 & 322 & 0.00 & 2.14 & 141 & 1420 & 93 & 0.00 \\
2.26 & 32 & 243 & 26 & 0.00 & 2.27 & 189 & 1180 & 153 & 1.00 & 2.17 & 347 & 2490 & 236 & 0.00 \\
2.28 & 46 & 269 & 37 & 0.00 & 2.15 & 141 & 1420 & 93 & 1.00 & 2.17 & 351 & 2020 & 261 & 0.00 \\
2.35 & 39 & 269 & 32 & 0.00 & 2.12 & 242 & 2580 & 143 & 1.00 & 2.15 & 223 & 1057 & 159 & 1.00 \\
2.30 & 41 & 271 & 31 & 0.00 & 2.15 & 311 & 2680 & 156 & 1.00 & 2.13 & 526 & 3160 & 408 & 1.00 \\
2.13 & 180 & 998 & 141 & 1.00 & 2.14 & 279 & 1820 & 217 & 0.42 & 2.16 & 306 & 1502 & 247 & 0.28 \\
2.11 & 269 & 1360 & 216 & 1.00 & 2.06 & 418 & 2970 & 252 & 0.18 & 2.04 & 1390 & 5394 & 1202 & 0.28 \\
2.12 & 208 & 1210 & 160 & 1.00 & 2.07 & 637 & 2830 & 524 & 0.39 & 2.13 & 227 & 1182 & 193 & 0.21 \\
2.15 & 198 & 996 & 160 & 1.00 & 2.10 & 401 & 2780 & 291 & 0.42 & 2.13 & 209 & 1312 & 169 & 0.21 \\
2.15 & 206 & 1120 & 160 & 1.00 & 2.07 & 411 & 3060 & 322 & 0.18 & 2.1 & 547 & 1898 & 461 & 0.16 \\
2.09 & 278 & 1570 & 226 & 1.00 & 2.12 & 867 & 3150 & 747 & 0.18 & 2.06 & 1370 & 5211 & 1172 & 0.46 \\
\hline
\end{tabular}


Table A1. Cont.

\begin{tabular}{|c|c|c|c|c|c|c|c|c|c|c|c|c|c|c|}
\hline \multicolumn{5}{|c|}{ 10HNAP Steel } & \multicolumn{5}{|c|}{ 2017-T4 Aluminium Alloy } & \multicolumn{5}{|c|}{ S355J2 Steel } \\
\hline$D f$ & $S q$ & $S z$ & $S a$ & $r$ & $D f$ & $S q$ & $S z$ & $S a$ & $r$ & $D f$ & $S q$ & $S z$ & $S a$ & $r$ \\
\hline 2.11 & 327 & 1500 & 272 & 1.00 & 2.11 & 526 & 3160 & 408 & 0.39 & 2.12 & 218 & 1498 & 137 & 0.29 \\
\hline 2.12 & 272 & 1370 & 219 & 1.00 & 2.11 & 574 & 3270 & 429 & 0.44 & 2.08 & 619 & 2404 & 520 & 0.29 \\
\hline 2.15 & 183 & 1130 & 146 & 1.00 & - & - & - & - & - & 2.14 & 191 & 1035 & 142 & 0.29 \\
\hline 2.13 & 180 & 1030 & 134 & 1.00 & - & - & - & - & - & 2.07 & 914 & 3621 & 802 & 0.34 \\
\hline 2.09 & 230 & 1310 & 186 & 0.50 & - & - & - & - & - & 2.08 & 607 & 2419 & 519 & 0.34 \\
\hline 2.12 & 160 & 1200 & 117 & 0.50 & - & - & - & - & - & 2.19 & 281 & 1509 & 222 & 0.24 \\
\hline 2.09 & 373 & 1620 & 311 & 0.50 & - & - & - & - & - & 2.17 & 282 & 1977 & 189 & 0.18 \\
\hline 2.11 & 190 & 1010 & 150 & 0.50 & - & - & - & - & - & 2.18 & 328 & 1464 & 293 & 0.28 \\
\hline 2.09 & 437 & 1760 & 380 & 0.50 & - & - & - & - & - & 2.07 & 547 & 1960 & 503 & 0.24 \\
\hline 2.09 & 489 & 2180 & 416 & 0.50 & - & - & - & - & - & 2.13 & 1180 & 5017 & 907 & 0.24 \\
\hline 2.16 & 433 & 1820 & 370 & 0.50 & - & - & - & - & - & 2.12 & 408 & 1765 & 327 & 0.42 \\
\hline 2.09 & 522 & 2060 & 452 & 0.50 & - & - & - & - & - & 2.15 & 544 & 1771 & 463 & 0.42 \\
\hline 2.07 & 400 & 1880 & 324 & 0.50 & - & - & - & - & - & 2.08 & 595 & 2642 & 479 & 0.55 \\
\hline- & - & - & - & - & - & - & - & - & - & 2.08 & 524 & 2471 & 405 & 0.55 \\
\hline- & - & - & - & - & - & - & - & - & - & 2.13 & 539 & 2135 & 488 & 0.33 \\
\hline- & - & - & - & - & - & - & - & - & - & 2.12 & 334 & 2204 & 247 & 0.55 \\
\hline- & - & - & - & - & - & - & - & - & - & 2.08 & 525 & 1811 & 495 & 0.26 \\
\hline- & - & - & - & - & - & - & - & - & - & 2.12 & 475 & 1601 & 417 & 0.23 \\
\hline- & - & - & - & - & - & - & - & - & - & 2.16 & 339 & 1309 & 282 & 0.60 \\
\hline- & - & - & - & - & - & - & - & - & - & 2.14 & 357 & 1242 & 312 & 0.23 \\
\hline- & - & - & - & - & - & - & - & - & - & 2.21 & 182 & 1055 & 154 & 0.33 \\
\hline- & - & - & - & - & - & - & - & - & - & 2.17 & 376 & 1473 & 293 & 0.15 \\
\hline- & - & - & - & - & - & - & - & - & - & 2.2 & 282 & 1265 & 221 & 0.31 \\
\hline- & - & - & - & - & - & - & - & - & - & 2.16 & 399 & 1248 & 348 & 0.18 \\
\hline- & - & - & - & - & - & - & - & - & - & 2.13 & 382 & 1182 & 339 & 0.39 \\
\hline- & - & - & - & - & - & - & - & - & - & 2.21 & 1130 & 4510 & 915 & 0.21 \\
\hline- & - & - & - & - & - & - & - & - & - & 2.15 & 595 & 3260 & 458 & 0.26 \\
\hline- & - & - & - & - & - & - & - & - & - & 2.16 & 989 & 3860 & 803 & 0.26 \\
\hline- & - & - & - & - & - & - & - & - & - & 2.2 & 867 & 3150 & 747 & 0.16 \\
\hline- & - & - & - & - & - & - & - & - & - & 2.15 & 574 & 3270 & 429 & 0.18 \\
\hline- & - & - & - & - & - & - & - & - & - & 2.14 & 189 & 1180 & 153 & 0.26 \\
\hline- & - & - & - & - & - & - & - & - & - & 2.17 & 242 & 2580 & 143 & 0.16 \\
\hline- & - & - & - & - & - & - & - & - & - & 2.18 & 311 & 2680 & 156 & 0.16 \\
\hline
\end{tabular}

\section{References}

1. Qian, J.; Fatemi, A. Mixed mode fatigue crack growth: A literature survey. Eng. Fract. Mech. 1996, 55, 969-990. [CrossRef]

2. Tomczyk, A.; Seweryn, A. Experimental investigation and modeling of damage accumulation of EN-AW 2024 aluminum alloy under creep condition at elevated temperature. Materials 2021, 14, 404. [CrossRef]

3. Merson, E.; Danilov, V.; Merson, D.; Vinogradov, A. Confocal laser scanning microscopy: The technique for quantitative fractographic analysis. Eng. Fract. Mech. 2017, 183, 147-158. [CrossRef]

4. Cisko, A.; Jordon, J.; Avery, D.; Liu, T.; Brewer, L.; Allison, P.; Carino, R.; Hammi, Y.; Rushing, T.; Garcia, L. Experiments and Modeling of Fatigue Behavior of Friction Stir Welded Aluminum Lithium Alloy. Metals 2019, 9, 293. [CrossRef]

5. Djukic, M.B.; Sijacki Zeravcic, V.; Bakic, G.M.; Sedmak, A.; Rajicic, B. Hydrogen damage of steels: A case study and hydrogen embrittlement model. Eng. Fail. Anal. 2015, 58, 485-498. [CrossRef]

6. Martelo, D.; Sampath, D.; Monici, A.; Morana, R.; Akid, R. Correlative analysis of digital imaging, acoustic emission, and fracture surface topography on hydrogen assisted cracking in Ni-alloy 625+. Eng. Fract. Mech. 2019, 221, 106678. [CrossRef]

7. Slámečka, K.; Šesták, P.; Vojtek, T.; Kianicová, M.; Horníková, J.; Šandera, P.; Pokluda, J. A Fractographic Study of Bending/Torsion Fatigue Failure in Metallic Materials with Protective Surface Layers. Adv. Mater. Sci. Eng. 2016, 2016, 1-6. [CrossRef]

8. Branco, R.; Costa, J.D.M.; Berto, F.; Razavi, S.M.J.; Ferreira, J.A.M.; Capela, C.; Santos, L.; Antunes, F. Low-cycle fatigue behaviour of AISI 18Ni300 maraging steel produced by selective laser melting. Metals 2018, 8, 32. [CrossRef]

9. Fonte, M.; Romeiro, F.; Freitas, M. Environment effects and surface roughness on fatigue crack growth at negative R-ratios. Int. J. Fatigue 2007, 29, 1971-1977. [CrossRef]

10. Macek, W.; Branco, R.; Trembacz, J.; Costa, J.D.; Ferreira, J.A.M.; Capela, C. Effect of multiaxial bending-torsion loading on fracture surface parameters in high-strength steels processed by conventional and additive manufacturing. Eng. Fail. Anal. 2020, 118, 104784. [CrossRef] 
11. Quinn, J.B.; Quinn, G.D.; Kelly, J.R.; Scherrer, S.S. Fractographic analyses of three ceramic whole crown restoration failures. Dent. Mater. 2005, 21, 920-929. [CrossRef]

12. Huang, H.M.; Tsai, C.M.; Chang, C.C.; Lin, C.T.; Lee, S.Y. Evaluation of loading conditions on fatigue-failed implants by fracture surface analysis. Int. J. Oral Maxillofac. Implant. 2005, 20, 854-859. [CrossRef]

13. Macek, W.; Owsiński, R.; Trembacz, J.; Branco, R. Three-dimensional fractographic analysis of total fracture areas in 6082 aluminium alloy specimens under fatigue bending with controlled damage degree. Mech. Mater. 2020, 147, 103410. [CrossRef]

14. Macek, W. Post-failure fracture surface analysis of notched steel specimens after bending-torsion fatigue. Eng. Fail. Anal. 2019, 105, 1054-1071. [CrossRef]

15. Branco, R.; Costa, J.D.; Berto, F.; Kotousov, A.; Antunes, F.V. Fatigue crack initiation behaviour of notched $34 \mathrm{CrNiMo6}$ steel bars under proportional bending-torsion loading. Int. J. Fatigue 2020, 130, 105268. [CrossRef]

16. Fonte, M.; Infante, V.; Reis, L.; Freitas, M. Failure mode analysis of a diesel motor crankshaft. Eng. Fail. Anal. 2017, 82, 681-686. [CrossRef]

17. Adamczak, S.; Zmarzły, P. Research of the influence of the 2D and 3D surface roughness parameters of bearing raceways on the vibration level. J. Phys. Conf. Ser. 2019, 1183, 012001. [CrossRef]

18. Lou, S.; Zhu, Z.; Zeng, W.; Majewski, C.; Scott, P.J.; Jiang, X. Material ratio curve of 3D surface topography of additively manufactured parts: An attempt to characterise open surface pores. Surf. Topogr. Metrol. Prop. 2021, 9, 015029. [CrossRef]

19. Li, J.; Du, Q.; Sun, C. An improved box-counting method for image fractal dimension estimation. Pattern Recognit. 2009, 42, 2460-2469. [CrossRef]

20. Leach, R. Characterisation of Areal Surface Texture; Springer: Berlin/Heidelberg, Germany, 2013; ISBN 9783642364587. [CrossRef]

21. Senin, N.; Thompson, A.; Leach, R.K. Characterisation of the topography of metal additive surface features with different measurement technologies. Meas. Sci. Technol. 2017, 28, 095003. [CrossRef]

22. Zak, K. Cutting mechanics and surface finish for turning with differently shaped CBN tools. Arch. Mech. Eng. 2017, 64, 347-357. [CrossRef]

23. Lu, W.; Zhang, P.; Zhai, W.; Wang, J.; Liu, X.; Jiang, X. Impact of surface topography on torsional fretting wear of the blade bearing interface under different lubrication conditions. Surf. Topogr. Metrol. Prop. 2019, 7, 015017. [CrossRef]

24. Podulka, P. The Effect of Surface Topography Feature Size Density and Distribution on the Results of a Data Processing and Parameters Calculation with a Comparison of Regular Methods. Materials 2021, 14, 4077. [CrossRef]

25. Giusca, C.L.; Leach, R.K.; Helary, F.; Gutauskas, T.; Nimishakavi, L. Calibration of the scales of areal surface topography-measuring instruments: Part 1. Measurement noise and residual flatness. Meas. Sci. Technol. 2012, 23, 035008. [CrossRef]

26. Dobrzanski, P.; Pawlus, P. Digital filtering of surface topography: Part II. Applications of robust and valley suppression filters. Precis. Eng. 2010, 34, 651-658. [CrossRef]

27. ISO-ISO 16610-21:2011-Geometrical Product Specifications (GPS)—Filtration—Part 21: Linear Profile Filters: Gaussian Filters. Available online: https://www.iso.org/standard/50176.html (accessed on 21 August 2021).

28. Țălu, Ş.; Matos, R.S.; Pinto, E.P.; Rezaee, S.; Mardani, M. Stereometric and fractal analysis of sputtered Ag-Cu thin films. Surf. Interfaces 2020, 21, 100650. [CrossRef]

29. Prajapati, D.K.; Ahmed, S. Analysis of micro-friction stir welding surfaces using fractal methodologies. Surf. Topogr. Metrol. Prop. 2020, 8, 035011. [CrossRef]

30. Cao, J.; Zeng, Z.; Zhang, F.; Guo, D.; Hou, Z. Effect of Cooling Rates on the Local-Overall Morphology Characteristics of Solidification Structure at Different Stages for High Carbon Steel. Metals 2021, 11, 1291. [CrossRef]

31. Issa, M.A.; Issa, M.A.; Islam, M.S.; Chudnovsky, A. Fractal dimension-a measure of fracture roughness and toughness of concrete. Eng. Fract. Mech. 2003, 70, 125-137. [CrossRef]

32. Charkaluk, E.; Bigerelle, M.; Iost, A. Fractals and fracture. Eng. Fract. Mech. 1998, 61, 119-139. [CrossRef]

33. Carpinteri, A.; Chiaia, B.; Cornetti, P. A scale-invariant cohesive crack model for quasi-brittle materials. Eng. Fract. Mech. 2001, 69, 207-217. [CrossRef]

34. Kotowski, P. Fractal dimension of metallic fracture surface. Int. J. Fract. 2006, 141, 269-286. [CrossRef]

35. Sahu, S.; Yadav, P.C.; Shekhar, S. Fractal Analysis as Applied to Fractography in Ferritic Stainless Steel. Metallogr. Microstruct. Anal. 2017, 6, 598-609. [CrossRef]

36. Macek, W. Fractal analysis of the bending-torsion fatigue fracture of aluminium alloy. Eng. Fail. Anal. 2019, 99, 97-107. [CrossRef]

37. Macek, W.; Branco, R.; Korpyś, M.; Łagoda, T. Fractal dimension for bending-torsion fatigue fracture characterisation. Measurement 2021, 184, 109910. [CrossRef]

38. Macek, W.; Branco, R.; Szala, M.; Marciniak, Z.; Ulewicz, R.; Sczygiol, N.; Kardasz, P. Profile and Areal Surface Parameters for Fatigue Fracture Characterisation. Materials 2020, 13, 3691. [CrossRef] [PubMed]

39. Macek, W.; Marciniak, Z.; Branco, R.; Rozumek, D.; Królczyk, G.M. A fractographic study exploring the fracture surface topography of S355J2 steel after pseudo-random bending-torsion fatigue tests. Measurement 2021, 178, 109443. [CrossRef]

40. Rozumek, D.; Faszynka, S. Surface cracks growth in aluminum alloy AW-2017A-T4 under combined loadings. Eng. Fract. Mech. 2020, 226, 106896. [CrossRef]

41. Kaplonek, W.; Nadolny, K. Advanced 3D laser microscopy for measurements and analysis of vitrified bonded abrasive tools. J. Eng. Sci. Technol. 2012, 7, 661-678. 
42. Tanaka, M.; Kato, R.; Fujita, T. Review of fractal analysis of fracture surfaces in various materials using three-dimensional images reconstructed by stereo matching method. Strength Fract. Complex. 2020, 12, 143-162. [CrossRef]

43. Carpinteri, A.; Spagnoli, A.; Vantadori, S. An approach to size effect in fatigue of metals using fractal theories. Fatigue Fract. Eng. Mater. Struct. 2002, 25, 619-627. [CrossRef]

44. Macek, W. Fracture Areas Quantitative Investigating of Bending-Torsion Fatigued Low-Alloy High-Strength Steel. Metals 2021, 11, 1620. [CrossRef]

45. Slámečka, K.; Ponížil, P.; Pokluda, J. Quantitative fractography in bending-torsion fatigue. Mater. Sci. Eng. A 2007, 462, 359-362. [CrossRef]

46. Macek, W.; Branco, R.; Costa, J.D.; Pereira, C. Strain sequence effect on fatigue life and fracture surface topography of 7075-T651 aluminium alloy. Mech. Mater. 2021, 160, 103972. [CrossRef]

47. Haigh, J.; Conover, W.J. Practical Nonparametric Statistics. J. R. Stat. Soc. Ser. A 1981, 144, 370-371. [CrossRef]

48. Pan, W.; Li, X.; Wang, L.; Mu, J.; Yang, Z. Influence of surface topography on three-dimensional fractal model of sliding friction. AIP Adv. 2017, 7, 095321. [CrossRef] 